\title{
Who Cares for Children? A Descriptive Study of Care-Related Data Available Through Global Household Surveys and How These Could Be Better Mined to Inform Policies and Services to Strengthen Family Care
}

\author{
Florence S. Martin ${ }^{1}$ • Garazi Zulaika ${ }^{1}$ \\ Published online: 29 April 2016 \\ (C) The Author(s) 2016. This article is published with open access at Springerlink.com
}

\begin{abstract}
There has been increasing recognition that the diversity and dynamic nature of family composition, structure, and living arrangements are intimately related to the key factors that support children's care and well-being and should be central to informing social policies and programs targeted to vulnerable children and their caregivers. The critical role of extended family has been recognized as key in efforts to strengthen family care for children. This paper argues that better use and mining of existing national household surveys, particularly the Demographic and Health Surveys (DHS) and Multiple Indicators Cluster Surveys (MICS), has great potential to inform child protection policy and programming. Important data that pertains to children's care and living arrangements are not extracted and presented in national reports, resulting in poor awareness of this information among child protection practitioners and policy makers. As a result, this potential is not currently being realized. To illustrate the strengths of the care-related information available through these datasets, we have conducted an analysis on orphanhood and living arrangements data based on available DHS and MICS surveys from 77 countries from sub-Saharan Africa, Latin America and the Caribbean, North Africa/West Asia/and Europe, Central Asia, and South and Southeast Asia. The paper presents some of the strengths and weaknesses of the data currently collected and identifies areas for better information use and accessibility.
\end{abstract}

Florence S. Martin is Director of Better Care Network.

Garazi Zulaika is an epidemiologist who works as a consultant for Better Care Network.

Florence S. Martin

Florence.martin@bettercarenetwork.org

1 The Better Care Network, 777 United Nations Plaza, Suite 3D, New York, NY 10017, USA
Information in these data-rich surveys regarding children's living arrangements must be better mined and communicated, so practitioners and policy makers have the tools to inform interventions to strengthen family care.

Keywords Kinship care · Orphanhood · Children's living arrangements $\cdot$ Family-based care

Over the last 50 years, there has been a growing understanding of the critical importance of family and the family environment for child development and well-being (Bowlby et al. 1965; Bowlby 1982; Schoenmaker et al. 2014). This realization is at the core of the international conventions and standards adopted by governments across the world, in particular the United Nations Convention on the Rights of the Child adopted in 1989 (UN CRC), and more recently, the Guidelines for the Alternative Care of Children endorsed by the United Nations General Assembly in 2009 (UN GA 2009).

A large body of empirical research in psychology, neuroscience, social work, and other disciplines has demonstrated the importance of investing in children's early years to support this critical period of child development (Shonkoff \& Phillips 2000; Browne 2009; Sroufe 2005). The role of a nurturing environment on early child development, focused in particular on the specific importance of the quality of parenting and stable care-giving relationships, is well evidenced in the literature and has become central to policies aiming to improve child well-being outcomes (Shonkoff \& Phillips 2000; Sonuga-Barke \& Kreppner 2012). Findings about the negative impact of emotional deprivation, neglect, and institutionalization for younger children have further established the central importance of a family environment for child well-being and development (Berens \& Nelson 2015; Fox et al. 2011; National Scientific Council on the Developing Child 2012; 
Nelson et al. 2011; Schoenmaker et al. 2014; van IJzendoorn et al. 2011; Roy et al. 2004). In a number of studies, children raised in a range of family environments, whether with biological families or foster and adoptive families, were found to do better than children raised in institutional care in terms of physical, cognitive, and socio-emotional development (Schoenmaker et al. 2014; Johnson \& Gunnar 2011).

As a result, reforms of child protection and alternative care systems for children deprived of family care, or who are at risk of being so, have been ongoing in almost all regions of the world (McCall et al. 2014; Williamson \& Greenberg 2010). These reforms have particularly focused on shifting away from the use of residential care and strengthening the capacity of parents and families to care for their children (Browne 2009; Bakermans-Kranenburg et al. 2011; Better Care Network \& UNICEF 2015a).

At the beginning of the 1980s, the HIV/AIDS pandemic focused the attention of policy makers and researchers in the humanitarian aid and development communities on the importance of family care in the context of socioeconomic stresses and emergencies. The "orphan crisis" highlighted in seminal reports such as Children on the Brink (Hunter \& Williamson 1997; UNAIDS et al. 2004; UNICEF 2004) revealed the devastating impact of the HIV/AIDS pandemic on children's care situations and overall well-being. Spiraling numbers of parental deaths in high HIV/AIDS prevalence countries, drove increasing numbers of children into the care of extended families or communities, child-headed households, or into fractured and poorly functioning alternative care systems, which were most commonly residential care facilities (Meintjes et al. 2007; UNICEF 2006; Richter et al. 2004).

A number of studies explored orphanhood prevalence in sub-Saharan Africa and sought to better understand the particular vulnerability of orphaned children as compared to children who had biological parents in relation to a range of socioeconomic outcomes. Although the findings were mixed, most studies found that orphaned children experienced poorer educational outcomes (Bicego et al. 2003; Case et al. 2004) and to a lesser extent, poor health, and nutritional outcomes (Magadi 2011; Monasch \& Boerma 2004).

However, as a growing body of evidence was gathered and programs deployed to respond to the orphan crisis, it became clear that other factors beyond parental death were affecting children's care situations and their well-being outcomes (Akwara et al. 2010; Ainsworth \& Filmer 2006; Beegle et al. 2009; Mishra \& Bignami-Van Assche 2008; Richter et al. 2009; UNICEF 2011). Research findings in a range of countries in Eastern and Southern Africa, for example, highlighted that while "orphanhood" was a key indicator of child vulnerability, other factors seemed to play a more significant role in child well-being and development, including household poverty and gender (Campbell et al. 2010). In the review conducted by Beegle et al. (2009) on trends in orphanhood and living arrangements and the links between the two in sub-Saharan Africa, they highlighted "the substantial variability" in the negative impacts of orphanhood in relation to child health and education across these countries (p.2) and pointed to the variability of resilience in the extended family network as well as changing childcare patterns as possible explanations. The authors called for more research on children's living arrangements and changes in child care patterns in various settings including in low HIV prevalence countries.

More recent research has reinforced these findings. A study by UNICEF (2014) has explored the utility of existing markers of child vulnerability, based on the UNICEF and UNAIDS definition of a child made vulnerable by HIV/ AIDS. Reviewing data from 11 countries selected to represent a range of HIV prevalence rates and geographic areas, the study found that "household wealth, a child's living arrangements, and household adult education emerged as the most powerful and consistent factors associated with key health and social outcomes of child vulnerability" (p.3). While orphanhood status was independently associated with some key outcomes, such as schooling, child labor, and birth registration, living arrangement was identified as a strong marker of well-being, independent of orphanhood status. In addition, children living with those other than their parents were found to fare worse on almost every outcome (UNICEF 2014).

Others studies have also questioned the shifting definition of orphanhood introduced in the AIDS context that aggregates children who have lost one parent ("single orphan") with children who have lost both parents ("double" or "true" orphans) (Meintjes \& Giese 2006; Belsey \& Sherr 2011; Sherr et al. 2008). These studies highlighted the potential for confusion and consequent risk of inappropriate approaches to meeting these children's needs. As a result, they argued for better monitoring of paternal and maternal deaths separately to assess more precisely the impact of HIV/AIDS on these children. This early emphasis on the "AIDS Orphan," later extended to "other vulnerable children" (UNAIDS et al. 2004), has also been criticized as having created the misperception that there were millions of children without any type of parental or family care. This narrow focus on parental death that ignores the diversity of children's care situations in families (including the role of other caregivers within the extended family) has too often led to the rapid growth of residential care in subSaharan Africa and not to expanding support services for these children's families and caregivers (Richter et al. 2009; Williamson \& Greenberg 2010).

There has been an increasing recognition that understanding the diversity and dynamic nature of family composition, structure, and living arrangements, as well as other key factors that impact children's care and outcomes, is critical to informing social policies and programs targeted to vulnerable children and their caregivers (Hosegood 2008; Beegle et al. 2009; Nyamukapa \& Gregson 2005). The critical role of 
extended family care (kinship care) and other forms of informal care has been highlighted as central to efforts to strengthen family care for children (Abebe 2009; Abebe \& Aase 2007; Roby 2011). The framework and values underpinning many interventions for "orphans" has also been criticized by some as being too Eurocentric for not recognizing sufficiently the reality of caregiving arrangements in the African context, including the role extended family care and foster care play in the context of children without parental care (Drah 2012).

Moreover, the current momentum for reforms of care and protection systems for children in low- and middle-income countries has also been informed by research that has found that there are, in fact, very few orphans in alternative care, including in the so-called orphanages. In countries where research has been conducted, between 80 and $90 \%$ of children in residential care were found to have at least one living parent and the majority had both parents living (Browne 2005; Browne et al. 2006; Carter 2005; Csaky 2009; Martin \& Sudrajat 2007). Research findings point instead to children being placed in residential care facilities by their parents and families due to a range of challenges these caregivers face in their capacity to care, including poverty, lack of access to social services, discrimination and social exclusion, and as the result of interpersonal or social crises and emergencies (Csaky 2009; Williamson \& Greenberg 2010).

These findings have led governments and other stakeholders to recognize the importance of shifting away from using residential care for children as the primary mode for addressing alternative care needs. Establishing better preventive and family support services is required to strengthen the capacities of families to care, to reduce unnecessary child-family separation, and to stop children going into alternative care in the first place. This approach is also called for by the UN CRC and the Alternative Care Guidelines, calling on States to ensure families have access to forms of support that enable them to care adequately for their children. (UN GA 2009, II. A.3).

In line with this shift, in February of 2013, the European Commission adopted an important Recommendation (2013/ 112/EU) on Investing in Children, stressing the importance of early intervention and preventative approaches. Adopted together with the new Social Investment Package (SIP), the recommendation makes quality childcare one of its key policy areas, hoping to break the cycle of disadvantage in early years and reduce the risk of child poverty and social exclusion. Of particular note, the recommendation addresses the importance of children's care directly, not only through support for parents' participation in the labor market but also through guidance on how to enhance family support overall and the quality of alternative care settings. In addition, the recommendation calls for adequate gatekeeping mechanism to prevent children from unnecessarily being placed in institutions and to stop the expansion of institutional care for children without parental care. The US government has also recently adopted a far-reaching new
Children in Adversity Action Plan that makes strengthening family care and preventing unnecessary child-family separation one of the principle objectives for US development assistance for vulnerable children globally (US Government 2012, Objective 2, APCA).

The body of research and policy highlighted above has underscored how the relationship between children's living arrangements, care situations, and child well-being outcomes is multifaceted and that understanding the interplay goes beyond whether a child is or is not an orphan. Data on family composition, structures, and relationships, including caregiving arrangements for children, are central to understanding how to strengthen family care and address risk factors that lead to child-family separation. Given the scarcity of national monitoring data on child protection issues in low- and middleincome countries, it is important that the sector explores the potential for using existing household-level datasets, particularly Demographic and Health Surveys (DHS) and Multiple Indicators Cluster Surveys (MICS) data, to be better informed of what existing data could offer and how this information could be leveraged to support more effective policies and interventions targeting at risk children and families. A number of international child protection organizations and agencies have illustrated through their work the potential for these large, nationally representative datasets to provide a better picture of the patterns and trends relating to children in households who are not living with a biological parent (Better Care Network 2013; 2015a; Child Frontiers 2012; Family For Every Child \& INTRAC 2012; Pullum et al. 2012; Roby 2011). Other important initiatives, such as the World Family Map Project (Child Trends 2013; 2014) have shown the potential of using internationally comparative data to map trends in family structures, family processes, and culture to explore the links between these indicators and certain outcomes of child well-being. Other efforts are also ongoing, including under the US Government Children in Adversity Action Plan, to improve the enumeration of children who are outside of family care, including those not captured by household surveys, in particular children in residential care and children living or working on the streets (Pullum et al. 2012; USAID Center of Excellence on Children in Adversity 2014).

This paper argues that better use and mining of national household surveys, particularly DHS and MICS, has the potential to significantly inform child protection policy and programming. Currently, this potential is not being realized. One key barrier that we will highlight is that, in many cases, useful data that pertain to children's care and living arrangements, are not extracted and presented in national reports. As a result, awareness of these potentially useful data among child protection practitioners and policy makers remains low. In order to illustrate the range of care-related information available through the DHS and MICS datasets, we have conducted a descriptive analysis of data on orphanhood and living arrangements based 
on available DHS and MICS from 77 countries across a wide geographic range of countries, including states in sub-Saharan Africa, Latin America and the Caribbean, North Africa/West Asia/and Europe, Central Asia, and South and Southeast Asia.

In this article, we highlight some of the key findings around children's living arrangements in these 77 countries in order to convey the great potential that these data hold for future research, policy, and practice concerning children's care. The paper presents some of the strengths and weaknesses of the data currently collected and identifies areas for better use and accessibility of the information. These available datasets must not only be explored and better mined but, ultimately, must also be made available to practitioners and policy makers who rely on these data to inform interventions to strengthen family care. An analysis of the relationships between different living and care arrangements and child well-being outcomes for the 77 countries is beyond the scope of the present paper, but examples from the literature are given as illustrations of possible useful links that could be further explored.

\section{Sources of Data and Methodological Approach}

\section{An Overview of Care-Related Data in the Current DHS and MICS}

National household surveys provide critical data to monitor population-level patterns and trends in relation to key sociodemographic indicators at national and subnational levels that can also be used to draw important comparisons between countries at both regional and international levels. Demographic and Health Surveys (DHS) have been conducted in middle to low-income countries by national statistical agencies with support from Measure DHS and USAID since the mid-1980s in over 90 countries. The DHS is now in phase 7 (2013-2018). The survey includes three main questionnaires (Household, Woman's and Man's Questionnaires) and provides nationally representative data on health and population indicators, including information on fertility, maternal and child survival, immunization, water and sanitation, education, and living arrangements to name a few. In addition, the DHS has included questionnaire modules on a range of specific topics such as domestic violence, female Genital mutilation (FGM), fistula, and out-of-pocket expenditures, among others (The DHS Program Overview 2015).

Since 1995, Multiple Indicators Cluster Surveys (MICS) have been conducted with support from UNICEF, in more than 100 countries, tracking progress and trends on more than 130 indicators, including 20 indicators relating to the Millennium Development Goals (MDGs) and other major international commitments relevant to the situation of women and children. MICS is now in its fifth round-MICS 5 (20122015). The survey also includes three main questionnaires
(Household, Woman, and Man Questionnaires) as well as a questionnaire on children under 5 years of age administered to the mothers or caretaker of these children. The questionnaires cover a wide range of issues, including child development, literacy and education, child labor, child discipline, water and sanitation, maternal and newborn health, marriage and union, FGM, birth registration, breastfeeding, sexual behavior, fertility, and tobacco and alcohol use among others.

These surveys provide particularly rich datasets through which changing household compositions and living arrangements, fertility and marriage, health and nutrition, literacy and access to education, poverty and deprivation, and other key indicators of child and family well-being are being tracked on a 5 -year basis for a nationally representative sample of households. Sample sizes are large, between 5000 and 30,000 households for DHS and on average 11,000 households for MICS in the current phase (DHS implementing partners \& ICF International 2000-2015; MICS implementing partners \& UNICEF 2000-2014). Both survey teams have been collaborating increasingly to ensure consistency in the use of indicators, to limit redundancies by targeting different countries, and to ensure comparability across the two surveys. Plans for greater collaboration with a third major global household survey program, the Living Standards Measurement Study (LSMS), supported by the World Bank, have also been recently announced (DHS 2015).

The relevance of the DHS and MICS datasets to children's care situations and well-being began to be recognized widely in the late 1990s in the context of countries with high HIV prevalence, particularly in sub-Saharan Africa. Analyses of the data on survival of parent status ("orphanhood") was produced and used to inform policy and programming at national and global levels to assist and respond to the particular needs of orphans and vulnerable children (OVCs). Many of these studies, as highlighted previously in this article, focused on the implications of orphanhood regarding certain child wellbeing indicators, in particular enrollment in school as well as health and nutrition, and have been used to compare the situation of orphaned children with nonorphaned children in households (Bicego et al. 2003; Case et al. 2004; Monasch \& Boerma 2004; Ainsworth \& Filmer 2006; Mishra \& Bignami-Van Assche 2008; Campbell et al. 2010). A few went beyond parental death to look at whether a child lived with his/her mother or/and father and how these living arrangements related to key indicators of child well-being such as access to education or health (Case et al. 2004; Beegle et al. 2009). These studies have mainly been within the context of sub-Saharan African countries with high HIV/AIDS prevalence with some important exceptions, including Ainsworth and Filmer (2006) and Akwara et al. (2010).

However, the DHS and MICS core questionnaires contain a number of indicators in relation to children's living arrangements and relationship to the head of the household regardless 
of country or HIV/AIDS prevalence. These data are collected under "Household Characteristics" and is part of the basic household schedule. For children $0-18$, the great majority of countries also collect data on parental survival and orphanhood. Previously when included, these data were collected for all children under 15 years of age who were living in a household; however, more recent DHS and MICS surveys have shifted the criteria to now also include children 15-17 living in households. These data are keys not only to understanding the extent of parental loss (maternal or paternal "orphans"/double orphans) found within a country but also for teasing apart the extent to which parental loss drives children's living arrangements and the resulting well-being indicators previously mentioned. Most importantly, when extracted and analyzed concurrently, the data provide critical information about the prevalence of children living out of parental care and the survival status of that parent.

Additionally, because the DHS and MICS surveys are a form of repeated cross-sectional studies, they can also provide important information about changes in prevalence over time, particularly where a country has had a number of surveys completed. In turn, these data can highlight patterns and trends in children's living arrangements and orphanhood at both national and subnational level and can be disaggregated to look more closely at factors such as gender, age, wealth, and geographical location, that may be relevant to children's living situations, protection, and well-being.

The structure of the Household Schedule allows for analysis of the relationship between the children in a particular household and the head of that household. Although there are some variations in the range of possible relationship categories provided, there is general consistency for most key categories such as being the grandchild, sibling, foster child, or unrelated to the household head. These data are systematically collected but rarely extracted and analyzed in the national reports, despite their clear relevance to children's care situations. Studies by Ainsworth and Filmer (2006) and Beegle et al. (2009) are two groundbreaking studies that did so, using DHS and MICS data from countries in sub-Saharan Africa. Although the data are an imperfect proxy measure for caregiving arrangements (as it does not provide actual information as to who the legal or de facto caregiver is for a particular child in that household), it is a clear measure of whether a child is living within or outside of family care. This information is key to understanding the extent and patterns of informal alternative care, particularly kinship care, in a given country which, in turn, is critical to inform policies seeking not only to strengthen parental care and to prevent harmful separation but also to support adequate family care and family-based alternative care. In combination with data on poverty, access to basic services, gender, violence, and other indicators of vulnerability, the data can inform strategies on how best to target social protection and family support programs to ensure appropriate care for children.
Most pressingly, these data are available and, in most cases, already collected. The fact that they are not extracted or analyzed as a matter of course overlooks one immediate need that can be addressed without major investment of resources or time. Awareness of the availability of this information and its relevance to a range of policies and services that can support vulnerable families, such as social protection, early childhood education, and livelihood strategies, is lacking. With the backdrop of numerous government priorities competing for data to measure progress on a range of indicators, data on family structures and caregiving may, at first, appear less pressing. However, the sharp focus on HIV/AIDs has drawn international agencies and donors to grapple with orphanhood and this, in turn, has ensured that data on parental survivorship be included in national surveys of high HIV/AIDS prevalence countries, and increasingly others. Nonetheless, the growing recognition that data on children's care and living arrangements are relevant to child well-being outcomes has not yet translated into strong advocacy pushing for the dissemination and use of these datasets.

Strong guidance for data collection agencies and data users, including national authorities, UNICEF country offices, policy and research bodies as well as donors, about the importance of the data and how to systematically extract and use them is clearly lacking. Similar data are used routinely in high-income countries to inform policies targeted to particularly vulnerable families, with the clear aim of strengthening parental capacity and addressing risk factors associated with child-family separation and inadequate family care (OECD 2011; OECD 2015; US Census Bureau 2012). Ensuring that similar analysis is conducted in low- to middle-income countries based on available household-level surveys, as well as other available datasets, should be a priority. Taking into account the fact that these data currently exist, extraction and use of the data has few to no additional resource implications for these countries. Meanwhile, the resulting findings will provide a rich and critical information base for national authorities, donors, and service providers to inform child- and family-centered policies and services.

\section{Methodological Approach}

This paper sets out to present preliminary analysis of the orphanhood and living arrangement data available in the Standard DHS and MICS datasets. The following analysis is based on the evidence provided by 77 countries that have had one of the two surveys conducted in the country after the year 2000, have collected data on parent survival status, and have had an unweighted sample size of children living out of family care of over 100 . These sample size considerations try to account for the high variability found in the number of children living outside of parental care across countries. The DHS and 
MICS do not use living arrangements as one of the key indicators that decide sample size for the national surveys. Therefore, given that sampling errors quickly increase as sample sizes become smaller or disaggregated, a minimum unweighted count of 100 was used to adjust for changes in precision from one country to the next. The sample includes 8 countries from North Africa and West Asia, 5 countries from Central Asia, 13 countries from South and Southeast Asia, and 13 countries from Latin America and the Caribbean. Approximately half the countries analyzed $(n=39)$ were in sub-Saharan Africa. Of the sample, 28 countries are classified as low-income economies by the World Bank, 31 are lower middle-income economies, and 18 are upper middle-income economies (The World Bank 2015).

The data present information for children 0-14 due to the fact that until recently many countries only collected parent survival status data on this cohort of children. No data prior to MICS3 are included nor from any Standard DHS that was conducted prior to the year 2000. Data on parent living arrangements available through the DHS Stats Compiler are presented, and data that were unavailable through the tool and all MICS data were extracted and analyzed using the statistical software package SAS 9.4. To measure statistically significant levels of association, chi-squared tests and $t$ tests were run using a $5 \%$ alpha level. All country-level figures reported have accounted for sample weights; none are unweighted. Additionally, the data presented below represent the entire sample of individuals present in each country dataset; no country-level DHS exclusion criteria has been applied.

The data presented here represent children who were residing in households at the time of data collection. They do not include the most vulnerable cohort of children ages 0-17 who are not living in households. These data look at the relationship between the child and the head of the household. They do not provide information on the primary caregiver of the child. Moreover, the data presented do not account for multigenerational households across children not living with a biological parent; therefore, it is possible that a child who is reported as the grandchild of the household head is also cohabitating with an aunt or uncle, sibling, or other relative. Also to note, the available questionnaire categories that capture relationships to household head do not distinguish between maternal and paternal relatives, an area that may warrant closer attention in further data collection efforts.

\section{What Can We Learn From the Current Data About Children's Care?}

\section{Prevalence of Orphanhood}

Analysis of data from the latest available DHS and MICS surveys from 77 countries across five regions globally shows that "true orphanhood," the death of both parents, is fortunately a relatively rare occurrence for children under 15 . As is seen in Fig. 1, of the 77 countries included, 61 have a prevalence of double orphanhood that is under $1 \%$, and a majority (44) under $0.5 \%$. On average, the prevalence of double orphanhood for all children 0-14 living in households was $0.7 \%$. Not surprisingly, bearing in mind that the link between HIV/ AIDs and orphanhood has been well-established (Bicego et al. 2003), three countries are exceptional outliers in this context - the countries in southern Africa with the highest prevalence of HIV/AIDS: Lesotho (5.4\%), Zimbabwe (4.7\%), and Swaziland (3.6\%).

It is important to note that a low prevalence does not mean that considerable numbers of children are not affected by the death of their parents; after all, $0.2 \%$ of children in India is still almost 800,000 children under the age of 15 . As previously mentioned, these data only cover children living in households and do not include children living in residential care or on the streets. However, research on orphans in the orphanages has shown that often the majority of children in these institutions have surviving biological parents and that there are, in fact, remarkably few orphans (Carter 2005; Martin \& Sudrajat 2007; Csaky 2009; Williamson \& Greenberg 2010). This research suggests that the majority of double orphans are not in orphanages but are found in households. Therefore, to more comprehensively understand what parental loss means in terms of care for these children, one needs to go beyond the "orphanhood data" and examine the available data on children's living arrangements.

The death of one parent ("single orphanhood") affects a much larger proportion of children under 15 across the 77 countries. While on average, approximately $6 \%$ of children have lost a mother or a father, there are considerable differences between countries and regions. Countries in southern Africa with the highest prevalence of HIV/AIDS report markedly high rates of children under 15 whom have lost one parent, with at least one in every eight children in Lesotho, Swaziland, and Zimbabwe having lost a parent and, consequently, reporting a higher average of single parent death across the region at $8 \%$. Nonetheless, there are non-African countries that also report high prevalence rates such as Haiti (9\%) and Mongolia (6\%), demonstrating that Southern Africa is not the only region where children are disproportionately affected by the loss of a mother or a father. Across the 77 countries, however, the vast majority of children 0-14, approximately $93 \%$, have two living parents.

\section{Living Arrangements}

\section{Children Living with One or Both Biological Parents (in Parental Care)}

Data from the DHS and MICS show that, on average, the majority of children under 15 in these countries live with both parents, with $68 \%$ doing so across the 77 countries as seen in Fig. 2. However, there are countries that are 


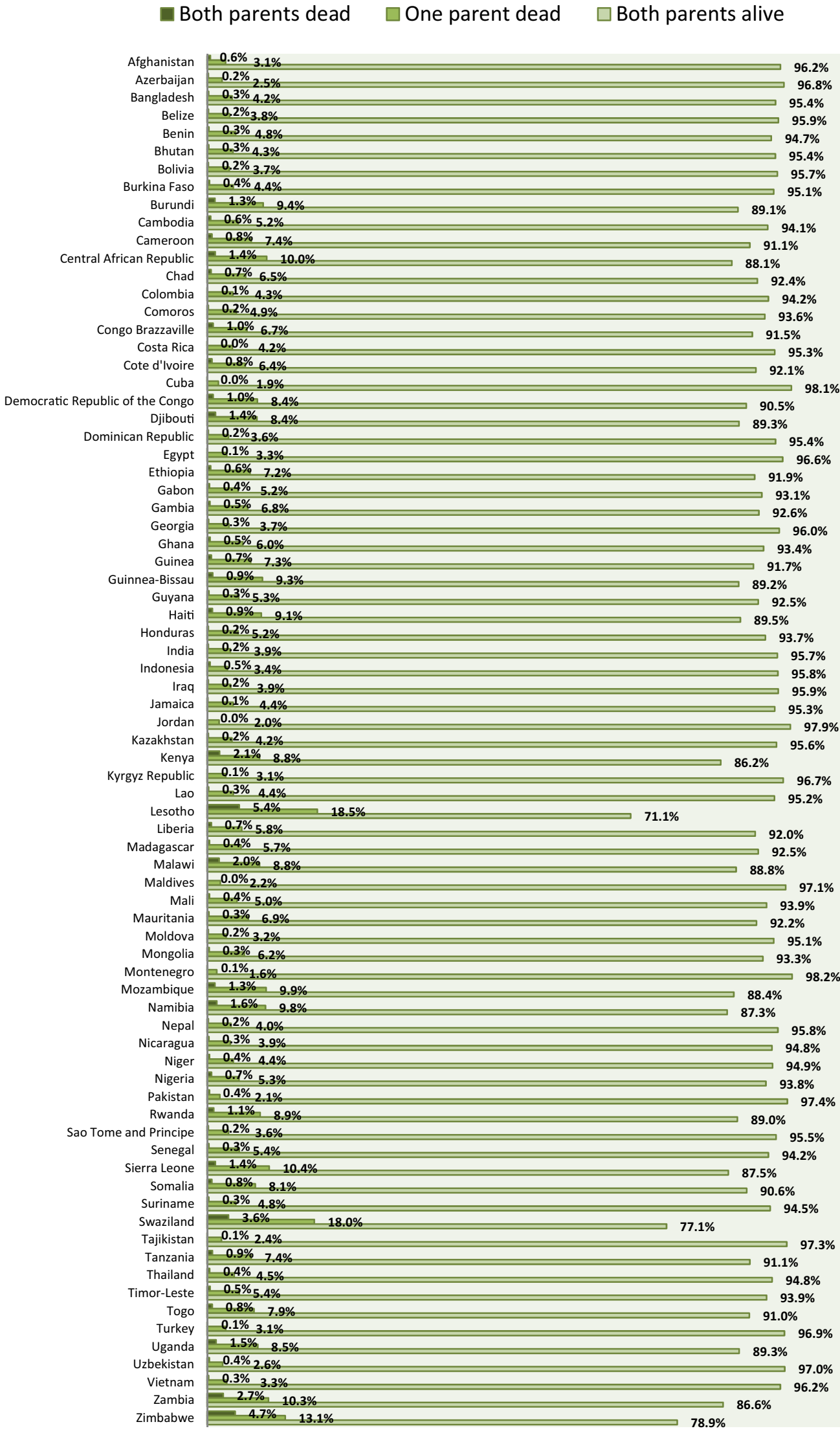

Fig. 1 The percent distribution of children ages $0-14$ by survival status of biological parent $(n=77)$ 
$\square$ Living with both parents $\square$ Living with a single biological parent $\square$ Living with neither biological parent

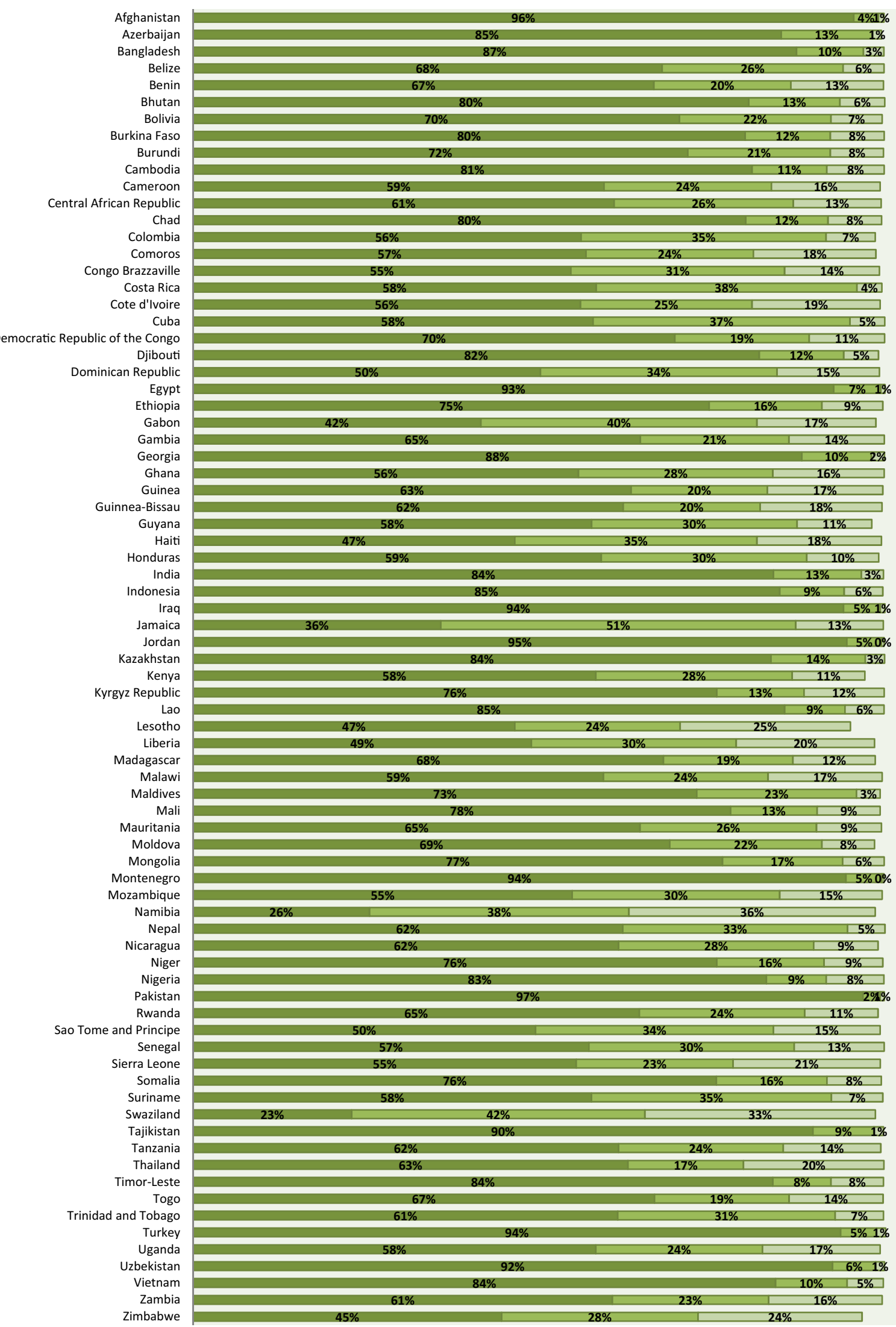


Fig. 2 Percent distribution of children ages 0-14 according to living arrangement. This figure illustrates the percentage of children living with neither, one, or both biological parents $(n=77)$

important outliers and see a very different reality on the ground. For example, Afghanistan reports $96 \%$ of children under 15 living with both parents, with Egypt, Iraq, Jordan, and Montenegro not far behind, each with over $94 \%$ of children under 15 living with both parents. On the opposite side of the distribution, fewer than one in four children 0-14 in Swaziland live with both biological parents $(23 \%)$, an astonishingly low proportion. As the country with the highest estimated prevalence of HIV/ AIDS at $28 \%$ (UNAIDS 2015), it may not come as a shock to find Swaziland together with other high HIV prevalence countries, such as Namibia (16\% estimated prevalence of HIV/AIDS and $26 \%$ of children living with both parents) with the fewest number of children living under parental care.

The data from DHS and MICS in 77 countries also highlight that a significant percentage of children live with only one parent. On average, across all surveyed countries, one in every five children under 15 live with only their mother $(18 \%)$ or their father $(3 \%)$. As with survival status and living outside of parental care, variability is seen by country. For example, in Latin American and the Caribbean, there is a higher prevalence of children under 15 living with only their mothers, including children found in Costa Rica (36 \%), Cuba (35\%), Suriname (32\%), Colombia (32\%), the Dominican Republic (30\%), and in Honduras (29\%). On the other hand, within the same region, Bolivia reports a considerably lower prevalence at $11 \%$. High prevalence rates of children under 15 living with their mothers only is not unique to that region and can also be found in Southern Africa (Swaziland, $40 \%$; Namibia $33 \%$ ), in West Africa (Gabon, $33 \%$ ), and in South Asia (Nepal, $30 \%$ ). In addition, the prevalence of children living with only their mothers can look remarkably different within countries. Zambia, for example, reports a prevalence of children under 15 living with their mothers that is only slightly below average at $19 \%$. Within Zambia, in the Western region, however, that prevalence is as high as $26 \%$. Interestingly, when looking elsewhere in the country, the adjacent Southern region and the Muchinga region to the Far East report prevalence rates of only 15 and $16 \%$, respectively (Better Care Network 2015a). Ultimately, this diversity is important to recognize given its profound implications for developing appropriate programs and policies that must fit individual country's contexts in order to better support family care and positively impact child well-being outcomes.

Similar trends are seen when looking at the prevalence of children under 15 living in households with only their biological fathers. Across the 77 countries for which data was analyzed, the prevalence ranges from $0.6 \%$ in
Pakistan and $0.7 \%$ in Tajikistan to as high as $9 \%$ in Liberia, and $8 \%$ in Cote d'Ivoire. Elsewhere in West Africa, neighboring countries have much lower prevalence of children living with only their fathers going as low as $3 \%$ in Mali and $2 \%$ of all children $0-14$ in Nigeria.

Separate from the DHS and MICS data presented here, one thing to note is that this diversity in children's living arrangement is not unique to low and middle-income countries. Data available from 23 OECD countries show that while the large majority of children in those countries live together with both their father and mother, there is "considerable cross-national variation with $95 \%$ of children living with both parents in Finland while only $65 \%$ do so in Belgium" (OECD 2010). Where on average $13 \%$ children in these countries live with their mother only and $2 \%$ with their father only, outliers such as the UK and US report rates of children living with only their mother at 28 and $23 \%$, respectively (this later figure is for children 0 18). Nonetheless, the sociocultural and economic factors behind these different living arrangements are certainly varied. To understand the extent to which these rates correlate with factors of family vulnerability, including the capacity to provide adequate care for children, requires further analysis that goes beyond living arrangements.

\section{Children Not Living with a Biological Parent (Outside of Parental Care)}

Globally, one in every ten children lives with neither biological parent. This figure represents a significant percentage of children who are not in parental care. This category of child living arrangement sees the highest levels of variability from one country or region to the next. While on average $10 \%$ of children under 15 are not living with either biological parent across the 77 countries, in places like Jordan $(0.4 \%)$ and Egypt $(0.6 \%)$, hardly any children live outside of parental care, while in countries like Namibia (36\%) and Swaziland (33\%), one in every three children lives under the care of someone other than a parent. By way of comparison, in the USA, an estimated $5 \%$ of children are not living with a biological parent (The Annie E. Casey Foundation 2015).

Strikingly, even when accounting for these regional variations and unequal distributions, the vast majority of children under 15 who are not living with a biological parent have two living parents $(73 \%)$. This reality may seem counter-intuitive at first as the discourse on orphanhood has traditionally underlined parental loss as a main driver of family separation and loss of parental care. However, as seen from the data presented above on orphanhood, while loss of a parent is relatively rare, living outside of parental care is much more common. Therefore, it should come as no surprise that, among 
children living with neither biological parent, nearly three out of every four children in this sample $(73 \%)$ have two living parents, and a significant percentage of these children have one (18\%). As Fig. 3 shows, on average, under one in ten children living outside of parental care has no surviving biological parent $(9 \%)$.

This is not to say that there are no outliers. For example, Afghanistan reports a very low prevalence of children not living with a biological parent $(0.8 \%)$ but, among those, a high percentage who are double orphans $(66 \%)$ while Cote d'Ivoire sees a high percentage of children who do not live with a biological parent (19\%) but, among those children, a relatively small percent of double orphans $(4 \%)$. These examples are presented to underscore the range of living arrangements found across different countries that must be carefully considered when tailoring programs and policies targeted to vulnerable children and families in order to be effective in a given context.

Overall, however, the picture that the data illustrate is that there are very significant numbers of children living without a biological parent, even when both parents are still living. Orphanhood is not the major driver leading to children living outside of parental care. Instead, it begs the following question: what are the primary reasons driving this phenomena and what is the consequent impact parent-child separation will have on children's well-being? These questions need answers in order to better inform policy and practices that address child and family vulnerability. In the context of the HIV/AIDS pandemic in South Africa, for example, an important focus of interventions by international and national agencies was on child-headed households. Taking into account the very high rates of parental mortality, it was thought that child-headed households were on the rise and needed to be targeted as the most vulnerable category of children. A statistical analysis of South Africa's 2006 General Household Survey, a national survey which mirrors the DHS and MICS questionnaires on household characteristics, found that, contrary to these assumptions, there had been no increase in the proportion of child-headed households in South Africa between 2000 and 2007 (Meintjes et al. 2009).

Even more striking, this analysis found that most children living in child-headed households were not orphans at all. Sixty-one percent of these children had both living parents, and $80 \%$ of them had a living mother. These children were not without family support with money sent by relatives and other adults being their main source of income $(71 \%)$. This analysis highlighted that many of the assumptions about these children's vulnerabilities were wrong, and while their situation was a cause for concern, the reasons behind their particular living and care arrangements demanded different policies and services than had been identified on the basis of mistaken assumptions. This powerful example illustrates how important statistical data on children's care and living arrangements can be to ensure appropriate and effective interventions to support child well-being.

As mentioned previously, the DHS and MICS surveys can also provide important information about changes in prevalence over time since they reoccur periodically in participating countries. These data can provide important insight into the impact of major social changes or emergencies and natural disasters on children's living arrangements, and indicate how such events may have impacted on the capacity of parents to care in this instance. A graphic illustration of this trend is provided in Fig. 4, taken from the DHS Legacy Statscompiler. Figure 4 illustrates clearly the impact of the 1994 Rwandan genocide on orphanhood for children under 15 years of age in the context of Rwanda's regional neighbors.

As we can see, these data do not only provide us with a one-time snapshot into the country but they can also highlight the broader and longer-term trends occurring in the area. For example, as shown in Fig. 5, across 12 countries in Eastern Africa that collected DHS data systematically, the percentage of children living without a biological parent remained relatively stable in the region between 1991 and 2014 (Better Care Network 2015b). One notable exception is Zimbabwe, which experienced a sharp increase in children living outside of parental care between 1999 and 2005 .

\section{Living Arrangements for Children Not Living with a Biological Parent}

To date, one of the major limitations of the presentation and accessibility of the DHS and MICS data is that existing data do not provide information on who these children are living with when they are not living with their parents. Both the Standard DHS and MICS surveys collect data around who lives in each household as part of the household listing; however, these data have historically not been extracted and made available through the organizations' online tools or included in the final country reports. As a result, the accessibility of the data is limited, given the cumbersome task of extracting raw data for considerably large samples. Although both DHS and MICS raw datasets are available free of charge for academics and other institutions who are able to process it, this extraction in itself requires resources that are often not available. In turn, the ability of country actors to make

Fig. 3 Percent distribution of children ages $0-14$ not living with a biological parent according to the survival status of the biological parent $(n=77)$ 
Both parents dead $\square$ One parent alive $\square$ Both parents alive

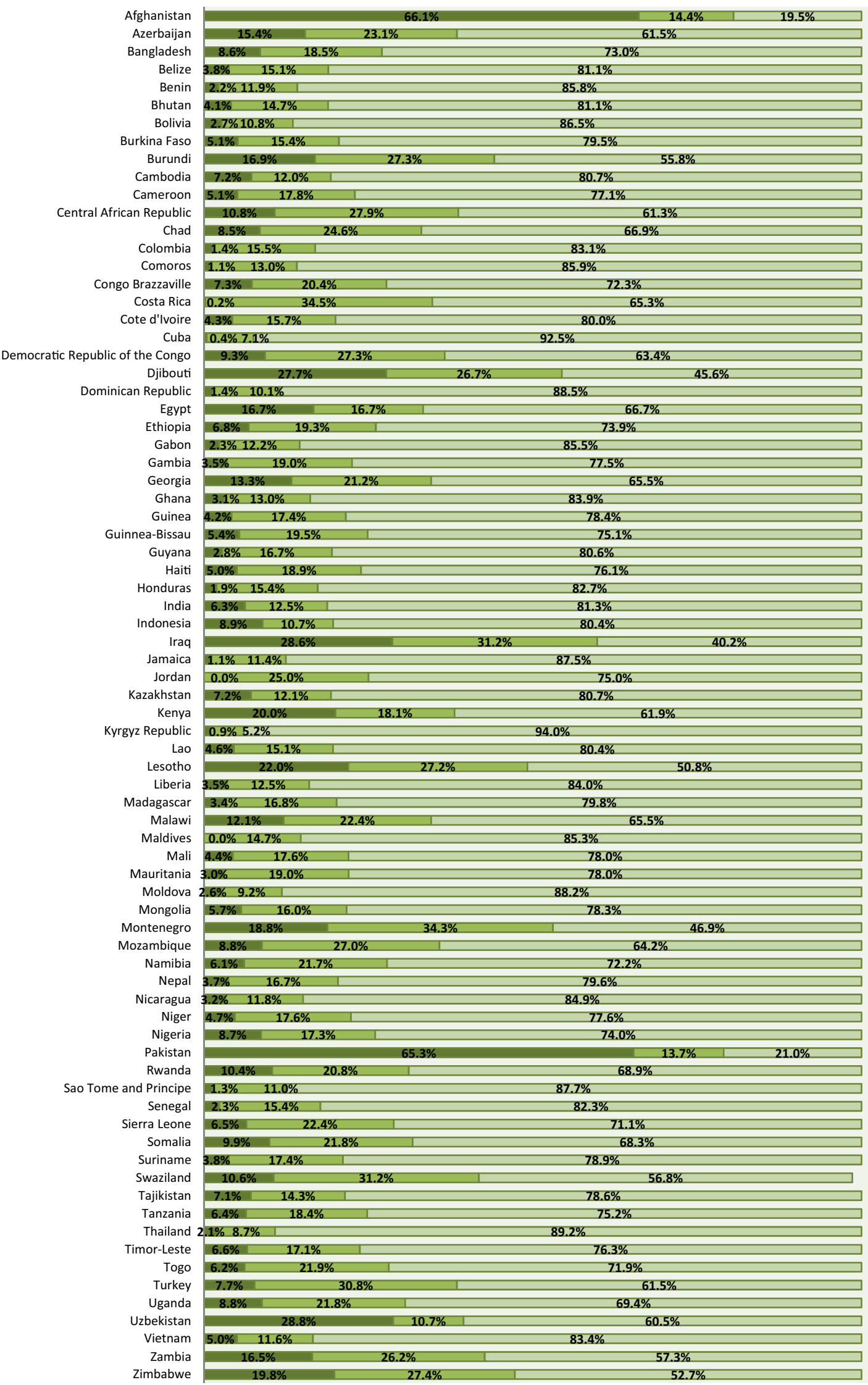




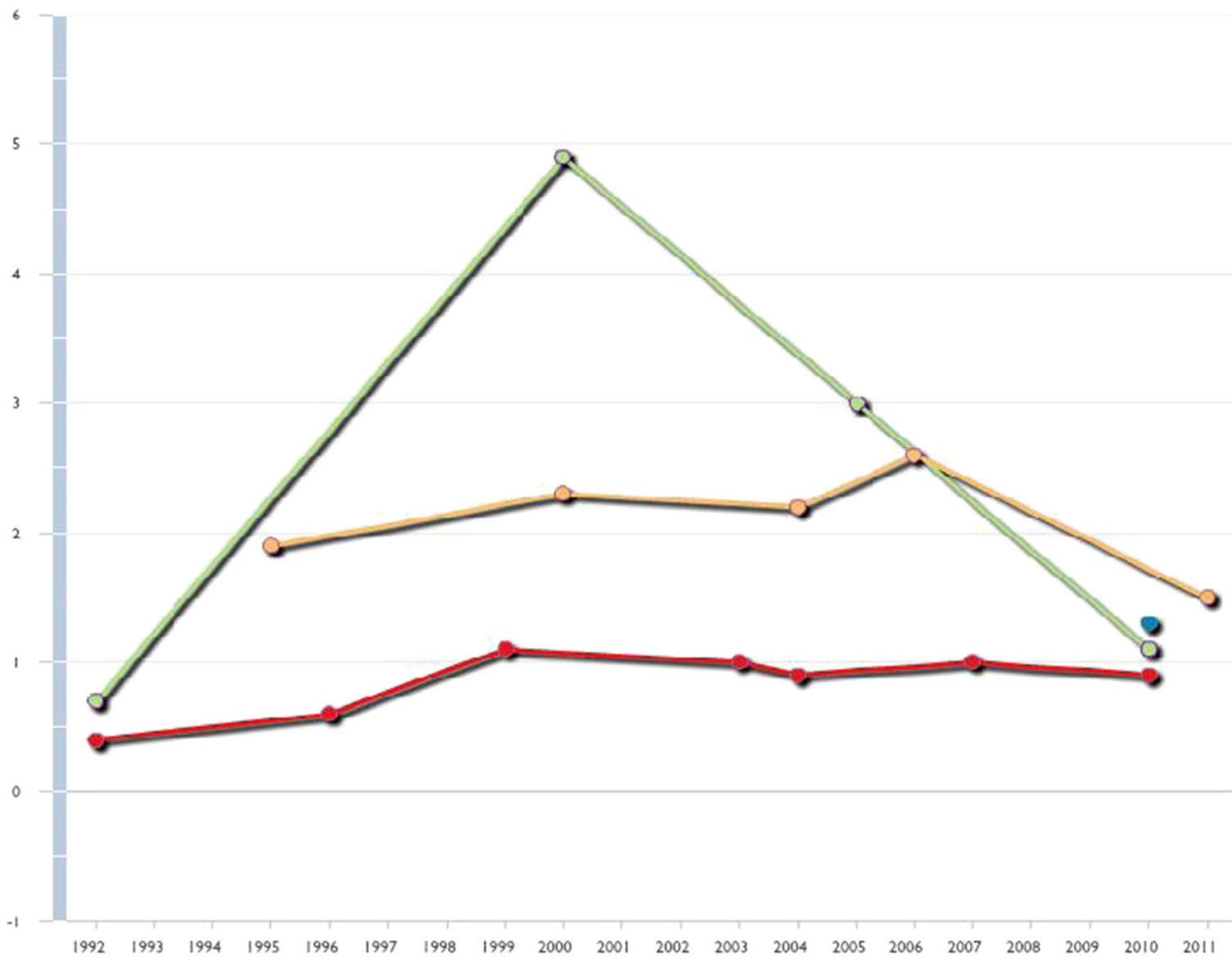

Countries

Burundi

$\square$ Rwanida

Tanzania

$\square$ Uganda

ICF International, 2012. The DHS Program STATCumpiler - hitp://www.statcompiler.com - September 152015.

Fig. 4 Percent of children who have lost both biological parents in Rwanda, Burundi, Kenya, and Uganda, 1992-2011. This graph, taken from the DHS Stats Compiler, illustrates the changes in orphanhood prevalence across these four countries between 1992 and 2011

30

25

15
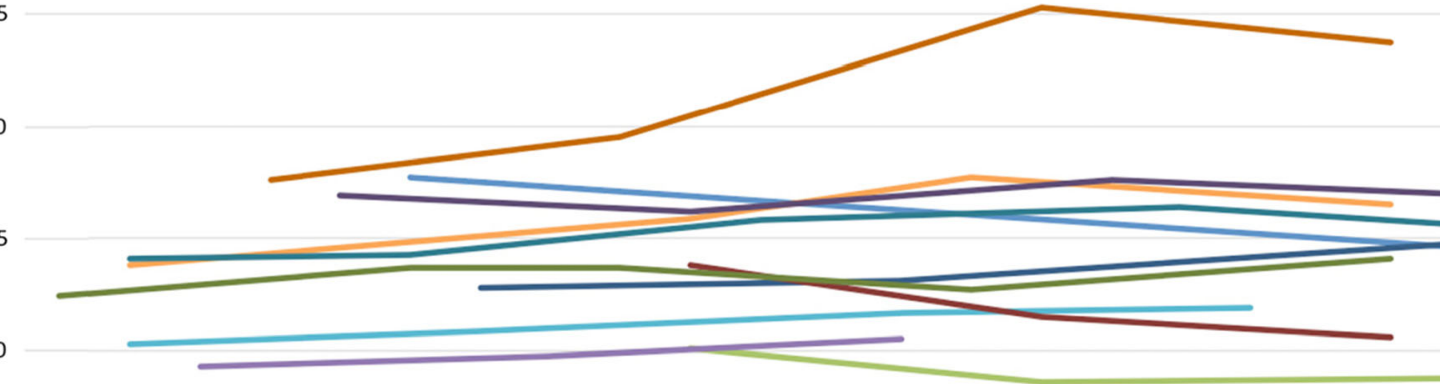

5

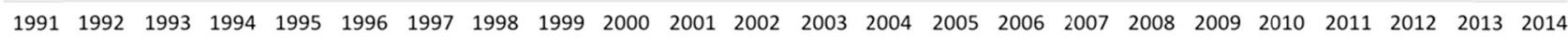

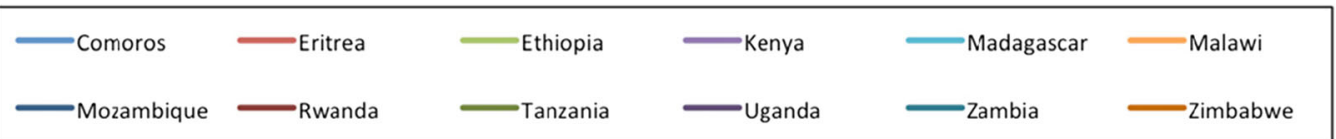

Fig. 5 Percent of children not living with a biological parent, DHS East Africa Region: 1991-2014. This graph illustrates the changing prevalence of children under the age of 15 living outside of parental care 
use of these data to inform their policies, services, and research is curtailed.

As mentioned earlier, the DHS and MICS surveys collect data on the relationship between children in a household and the head of that household, not specifically on the child's caretaker. Nonetheless, in the case of children not living with a biological parent, these surveys can powerfully indicate whether or not a particular child is living in a household with a relative, which is a strong if imperfect proxy indicator for family care. The data specify whether the child lives in a household headed by a particular family member such as his or her grandparent, aunt or uncle, sibling, a foster parent, or some other relative, or, alternatively, if the head of the household is a nonrelative. As such, the data can provide important indications of the scale and role kinship care plays for children who are not in parental care.

For countries seeking to (1) reform their child care and protection systems; (2) ensure more effective targeting of particular vulnerable populations for social protection or livelihood schemes; (3) ensure effective access to social services for children who are not in parental care; or (4) strengthen parental skills to prevent violence against children and guarantee maximum access to early childhood education interventions for particularly vulnerable children, these data are critical for understanding exactly whom to target and how best to reach them. Research has shown, for example, that the needs of older caregivers such as grandparents are quite different from the needs of younger caregivers (EveryChild \& HelpAge International 2012). Grandparents acting as primary caregivers for children were found to be more financially vulnerable and also more likely to face health issue, yet less likely to access sources of support. (JLICA 2009; Nandy \& Selwyn 2013). The packages of services and ways of accessing them may need to be different in contexts where grandparents are the primary caregivers, compared to contexts where younger caregivers such as aunts and uncles, siblings and cousins are playing that role.

The vast majority of children under 15 not living with either biological parent are living in households headed by a relative (94\%), as seen in Fig. 6. Kinship care is clearly playing a major role for these children. To give a sense of the sheer numbers of children in this type of living arrangement, for the 12 countries in East Africa alone (Burundi, Comoros, Ethiopia, Kenya, Madagascar, Malawi, Mozambique, Rwanda, Tanzania, Uganda, Zambia, and Zimbabwe), over 19 million children are living in kinship care, and $89 \%$ of them have at least one parent alive. This is a considerable number of children whose situations and needs, as well as those of their caregivers, need to be better understood and addressed (see Table 1).

One interesting lens the DHS and MICS data provide is the relationship category of "not related to the household head." Although a relatively small percentage of children under 15 who are not living with a biological parent are reported in this category (in our sample on average only $3 \%$ of all children living outside of parental care fell into this category), it is a group of children who may be particularly vulnerable given that they are "outside of family care," and understanding whom they live with, what their situation is, and what this situation means for their wellbeing should be a crucial area for future research. Additionally, more careful fieldwork is needed to ensure that the trends in relative and nonrelative care highlighted by the data reflect actual sociodemographic realities on the ground. The data readily show that context matters-and although great diversity across countries is apparent in the data, there appears to also be striking differences within certain countries when examining subnational level data. One example of this is found in Nigeria: $12 \%$ of children below the age of 18 are found not to be living with their parents in the South East while fewer than $2 \%$ do the same in the North West of the country (Better Care Network 2015d). This discrepancy speaks to the idea that there is no "one-size-fits-all" answer to understanding children's living and care structures globally.

The DHS and MICS questionnaires also provide for an additional category of relationship to the head of household that holds high potential for further research to better understand children's living and care situations. The surveys enable respondents to select for "foster and adopted children," and an average of $7 \%$ of children under 15 not living with a biological parent were identified as such. However, as highlighted by Ainsworth and Filmer (2006), the lack of clarity over what is meant by these terms is problematic. The DHS and MICS questionnaires provide a definition of "foster children" that is extremely broad and potentially confusing: "those under age 18 years of age living in households with neither their mother nor their father present." In other words, by definition, fostered or adopted children include all children in kinship care as well as in unrelated care. However, given the apparent overlap under this definition with other listed categories, it would seem that the definition of "fostered or adopted" is applied more narrowly in this context. On the other hand, the literature on formal foster care and adoption in many of the countries surveyed show that few of these have working formal foster care and adoption systems, so children classified under this grouping are likely to be in informal foster arrangements and adoption. Clarifying how this category is understood and recorded in different countries and contexts is critical to enable full use of these profoundly important data.

Moreover, the data can be disaggregated by age, sex, geographical location, or household wealth to also shed light on certain patterns of children's care that may be significant for those working to strengthen family care. The data clearly illustrate that the child's age is often significantly correlated 


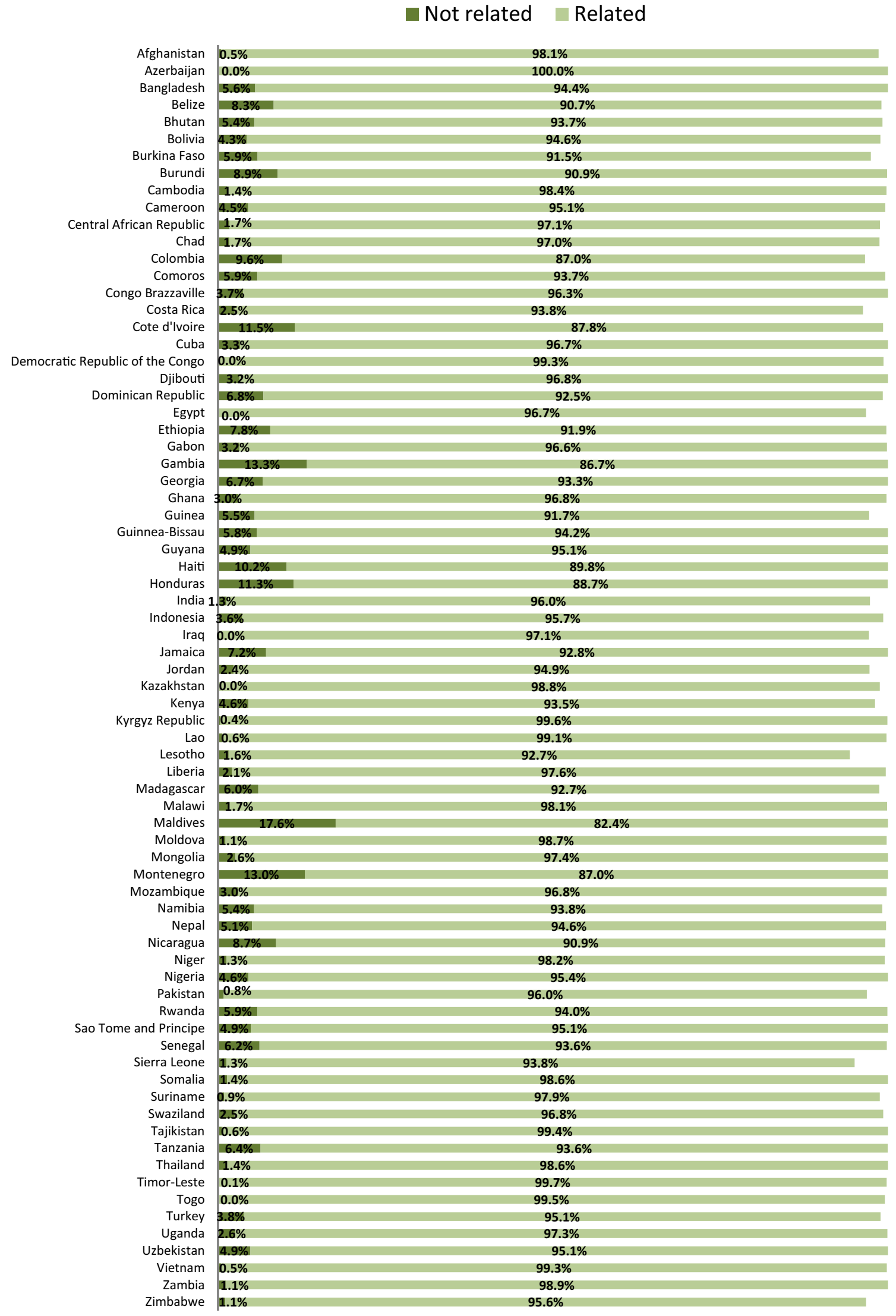

Fig. 6 Percent distribution of children $0-14$ living with relatives and nonrelatives among those living with neither biological parent $(n=75)$ 
Table. 1 Number of children 0-14 living in kinship care among children living with neither biological parent in East Africa

\begin{tabular}{|c|c|c|c|c|c|}
\hline Country & Survey & $\begin{array}{l}\text { Percent living outside } \\
\text { of parental care, } 0-14\end{array}$ & $\begin{array}{l}\text { Percent of children who } \\
\text { have at least one living } \\
\text { biological parent }\end{array}$ & $\begin{array}{l}\text { Percent of those } \\
\text { living in kinship } \\
\text { care, } 0-14\end{array}$ & $\begin{array}{l}\text { Number of children } \\
\text { in kinship care, } 0-14\end{array}$ \\
\hline Burundi & 2010 DHS & $10 \%$ & $86 \%$ & $91 \%$ & 415,933 \\
\hline Comoros & 2012 DHS & $18 \%$ & $99 \%$ & $94 \%$ & 52,417 \\
\hline Ethiopia & 2011 DHS & $9 \%$ & $91 \%$ & $91 \%$ & $3,482,393$ \\
\hline Kenya & 2003 DHS & $11 \%$ & $73 \%$ & $95 \%$ & $2,041,786$ \\
\hline Madagascar & 2008-2009 DHS & $12 \%$ & $97 \%$ & $93 \%$ & $1,091,839$ \\
\hline Malawi & 2010 DHS & $17 \%$ & $88 \%$ & $98 \%$ & $1,226,401$ \\
\hline Mozambique & 2011 DHS & $15 \%$ & $91 \%$ & $97 \%$ & $1,706,620$ \\
\hline Rwanda & 2010 DHS & $11 \%$ & $85 \%$ & $94 \%$ & 544,605 \\
\hline Tanzania & 2010 DHS & $15 \%$ & $94 \%$ & $93 \%$ & $3,114,671$ \\
\hline Uganda & 2011 DHS & $17 \%$ & $91 \%$ & $97 \%$ & $3,138,565$ \\
\hline Zambia & 2013-2014 DHS & $15 \%$ & $87 \%$ & $98 \%$ & $1,037,092$ \\
\hline Zimbabwe & 2010 DHS & $24 \%$ & $87 \%$ & $96 \%$ & $1,290,242$ \\
\hline Total & & $14 \%$ & $89 \%$ & $95 \%$ & $19,142,563$ \\
\hline
\end{tabular}

with whom the child is living with, as Fig. 7 from Uganda highlights (Better Care Network 2015c). Babies and infants not living with their parents are significantly more likely to be in the care of their grandparents than older children, and there are very few babies and infants in the care of unrelated persons. By the age of 5, however, aunts and uncles, other relatives, and nonrelatives begin to play a bigger role. Between the ages of 15 and 17, children who have married are also moving to households headed by their spouses.

In addition to the child's age, the geographical location of the household, particularly whether it is located in a rural or urban location, appears to be clearly linked in some countries to different living arrangements for children not living with a biological parent. In Ethiopia, for example, there are three times as many children who live with neither biological parent living in households located in rural areas compared to urban areas (Better Care Network 2015b). There are also clear differences in types of living arrangements between those two contexts, with proportionally more children (under 18) living with grandparents in rural areas than in urban areas. The reasons for this distribution may include children being left in the care of grandparents by parents who migrate to urban centers to look for work. It could also be that proportionally more children in older age groups migrate to urban centers without their parents and live in unrelated households to access higher education, which may otherwise not be available to them in rural areas.

Another interesting area for further research is around household wealth quintile. As seen in Fig. 8, when we look more closely at Ethiopia, households hosting unrelated children are also more likely to be in the richest wealth quintile. In Ethiopia, among children 0-17 living with neither biological parent, while only $3 \%$ of children living in households in the poorest wealth quintile report being unrelated to the household head, nearly $20 \%$ of children living in households
Fig. 7 Percent distribution of child relationship to household head among children $0-18$ living with neither biological parent in Uganda, according to age group

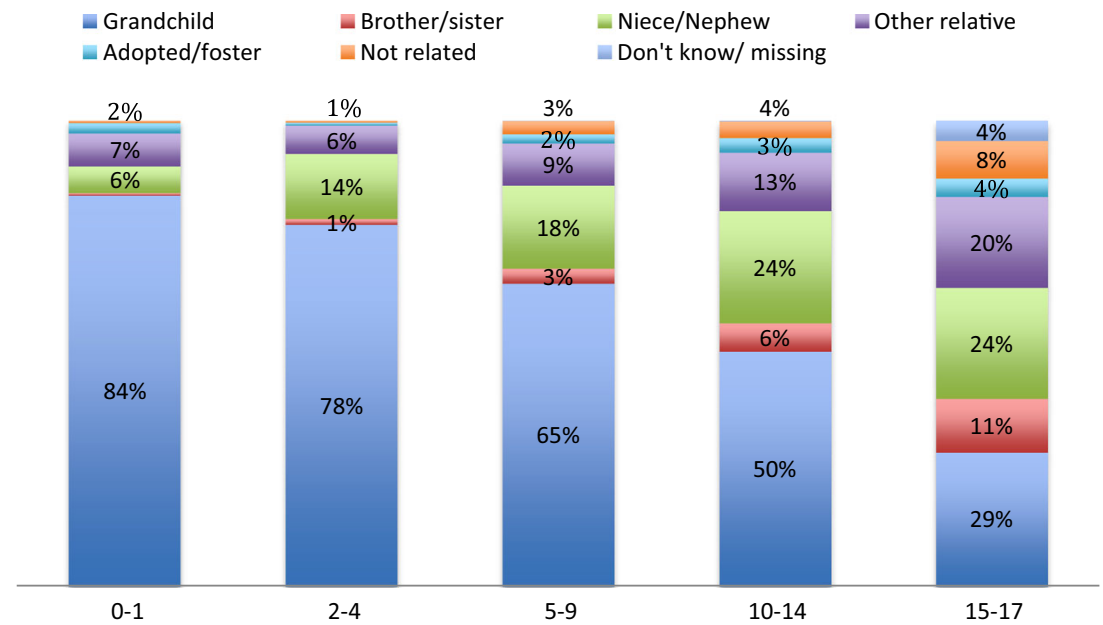




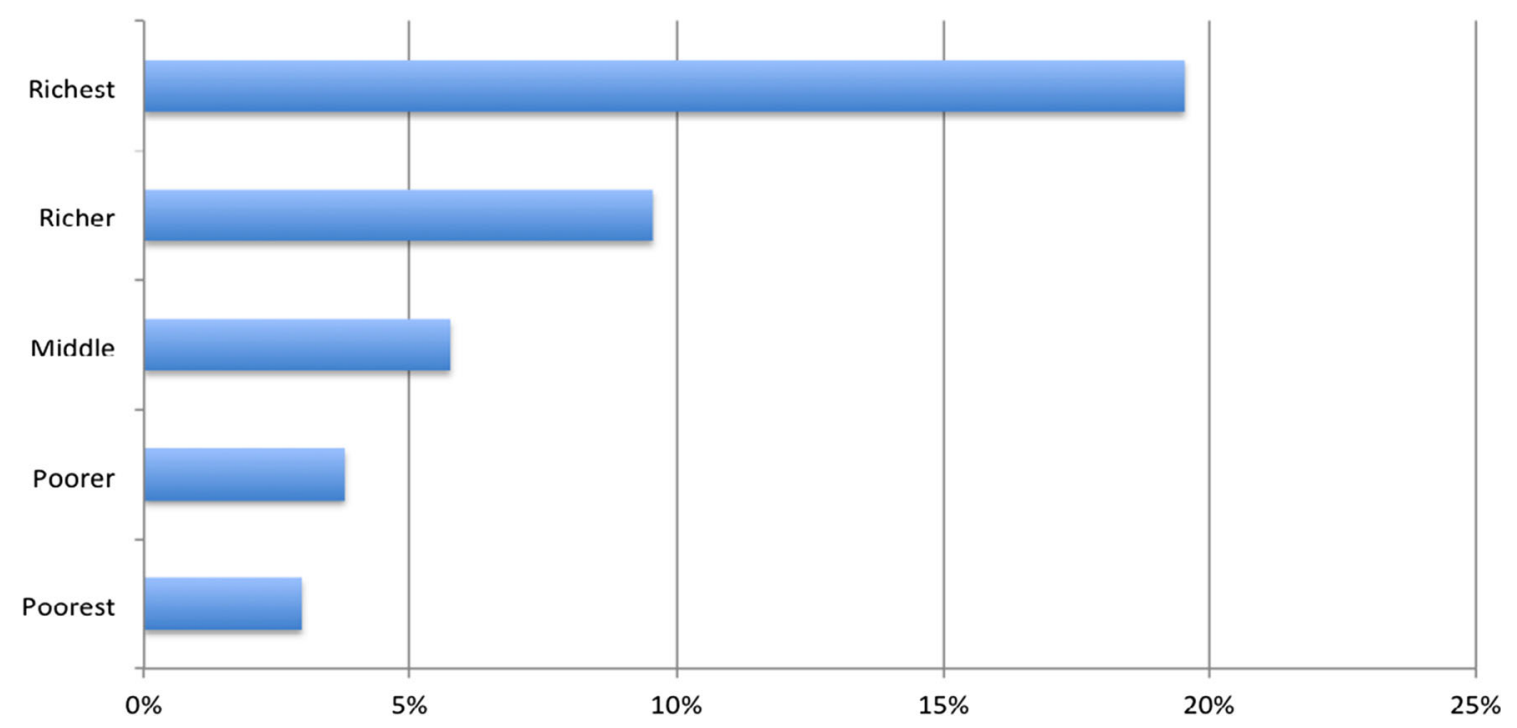

Fig. 8 Percent distribution of children 0-17 living in households headed by nonrelatives in Ethiopia, according to household wealth quintile

belonging to the richest quintile live in households where they are not related to the head of the household (Better Care Network 2015b). It is possible that wealthier households managing more resources are both concentrated in urban centers and more likely to provide opportunities like boarding for schooling or employment for domestic work to unrelated youth. Understanding these patterns and their implications for strengthening family care requires further analysis by researchers to better inform policies and services in these contexts. Lack of access to education has been found to be a major driver of placement in residential care in a number of countries including Indonesia and Liberia (Martin \& Sudrajat 2007; Better Care Network \& UNICEF 2015b). In countries such as these, data on children in relative and non-relative care should not only be disaggregated by factors such as ruralurban distribution, household wealth, age, and gender but also should look at individual outcomes that are captured in the datasets. For example, modeling the distribution of living arrangements against the availability of schools and child enrollment may provide important information around the role of education in driving children outside of family care or inform which variables better predict higher enrollment or improved school outcomes among children.

\section{Discussion}

This review of data on children's living arrangements and parental survivorship for 77 countries presents how these data can inform country-level and regional level patterns around orphanhood, household composition, and living arrangements for children who have lost one or both parents as well as for children who have living parents. We have also sought to highlight how these data provide some indication of the relationship between living arrangement indicators and factors such as age, sex, geographical location, and household wealth. Among the key findings is the reality that "true orphanhood" remains rare, excluding a number of countries in Southern Africa where the HIV/AIDS pandemic has had a devastating impact on parental mortality. In fact, the great majority of children globally have two living parents. However, the data also show that there is a sizeable percentage of children globally who are living with one parent only, most commonly their mother, even when their father is alive. Lastly, the most prominent picture that emerges from these 77 countries tells us over and over again that there is a striking percentage of children under 15 across all regions of the world who live outside of parental care even though they have two surviving parents. Reasons why children may not live with their parents are likely varied and could include reasons such as the following: parental migration in search of work, child migration to access education or work, cultural arrangements that support the transfer of children within families or communities, early marriage, child abandonment or separation, and child domestic work, among many others. Understanding the factors that lead to loss of parental care and how that loss impacts child wellbeing and outcomes is essential if governments are to strengthen the capacity of parents to care for their children adequately.

The data also clearly underline that the vast majority of these children remain in extended family care (kinship care). These findings underscore that for millions of children living outside of parental care, family support does not mean support from their parents, but rather includes a range of other caregivers who may have different needs.

It is important to note that the data presented here have a few limitations. First, as they currently stand, the DHS and MICS household schedules provide information regarding the 
household composition but say little regarding the child's primary caregiver. This is an important limitation because the possibility that children live in a household headed by one family member but are cared for by a second family member. The lack of specificity on care arrangements means that the particular needs for support of caregivers may remain hidden and programs may target the incorrect individuals to support these children most effectively. It may be the case that households composed of a number of adult relatives have better support mechanisms for child care than in households where the child's primary caregiver is also the head of the household. Fortunately, momentum in this area has led to newer surveys paying closer attention to identifying primary caregivers at least for children under 5 .

Second, and most notably, the information currently captured through household surveys reflects only a rigid snapshot of the structured household. Flows of communication, individuals, and funding that build the networks of each individual household remain hidden. The data cannot uncover whether nonorphaned children living with neither biological parent communicate with their parents, are visited by them, or are supported financially by them. It does not capture the stability of the household composition, leaving unknown the timing of when a parent left or whether the parent comes and goes routinely. These limitations highlight areas of study that require additional data to uncover children's dynamic care structures and relationships.

Structural differences also clearly matter in this context (Abebe \& Aase 2007). Children's care in multi-generational households, in polygamous households, and in extended community care where relationships and roles extend beyond the role of the individual "household" or parental unit must also be carefully considered to understand what challenges are faced by these caregivers and the children they care for as well as which services may be needed to support them effectively. A one-size-fits-all approach to family support is unlikely to succeed while potentially undermining existing sources of informal support. Yet, this analysis cannot be done without a more careful and informed understanding of children's living and care patterns. Better use of global households surveys and other key datasets, including census data, is a first crucial step toward this more informed approach to supporting family care.

In all of these households, sociocultural contexts and personal relationships are at play, making different types of care situations in themselves insufficient to determine whether a child is in a vulnerable situation or whether a particular living or care arrangement will necessarily lead to poorer child well-being outcomes. The literature, which primarily emanates from highincome countries, does indicate not only that certain family structures are associated with poorer outcomes for children in a number of well-being dimensions but also that those correlations are far more complex than what may appear at first glance. It has been argued that the stability of the family arrangement, rather than the particular structure, seems to have most impact on child well-being (Child Trends 2014; Waldfogel et al. 2010). There is, nonetheless, quite consistent research showing that, overall, children not living in parental care tend to have worse outcomes than those who do (UNICEF 2014) and that grandparents as caregivers experience more poverty and health issues (Apata et al. 2010; EveryChild and HelpAge International 2012; Leder et al. 2007). Understanding how these different family characteristics and children's care situations correlate with access to basic social services, including education, health, birth registration, child labor, poverty, and social exclusion, can inform policy makers and practitioners about what patterns of child vulnerability should be taken into consideration in their planning and approaches and in identifying which children and families could be targeted most effectively.

The clear international political commitment to preventing child and family separation highlighted earlier in this article requires means of measuring progress in implementation in that regard. This entails not only the availability of global data on children's living arrangements but also a reliable set of indicators of child and family vulnerability to separation. Developing such an indicator, or more likely, a set of indicators, is one of the key objectives of an international technical working group of the Child Protection Monitoring and Evaluation Reference Group (CP MERG 2014).

Ensuring that effective systems of data collection are available for children who are outside of parental or family care is a fundamental responsibility of the State as having ultimate responsibility for these children when parents and families are unable or unwilling to fulfill their prime responsibility toward these children (UN GA 2009, VII.A.69). Children living in households outside of family care can often be in vulnerable situations which can include living as domestic workers, those informally "fostered" or "left behind" and in the care of nonrelatives, children "boarding" or living with their employer or religious teacher, or children living in child-headed households. Children outside of households, including those in residential care, in detention facilities, or living and working on the streets, are also amongst the most vulnerable, yet data about the whereabouts and situations of these children is sorely lacking even when their care and well-being fall directly under the responsibility of the State (Pullum et al. 2012; Csaky 2009; Williamson \& Greenberg 2010; Save the Children 2013). Ensuring systematic and individual-level information is available for all these children should be complementary to efforts to make better use of household-level data to understand children's living and care situations.

Global household surveys are a remarkably useful source of data and have become "indispensable in economic and social policy analysis, development planning, programme management and decision-making at all levels" (DESA/UNSD 2005, p.4), most notably in lowand middle-income countries. These surveys have also 
become highly influential in shaping the development of national-level sociodemographic surveys in both content and format. The questionnaires are often integrated into nationally developed surveys and they have become the prime vehicle for measuring national implementation of internationally agreed commitments, such as the MDGs, and currently the development of the new Sustainable Development Goals (SDGs). As a result, these global household surveys largely dictate what information the international community deems important. Therefore, adequate and systematic collection of data on children's care situations and living arrangements is mandated, given the global recognition of the importance of family care for children and the need to support and strengthen the capacity of families to care adequately for their children and prevent unnecessary separation.

DHS and MICS represent a considerable investment of financial and human resources by the international development community and national authorities. The fact that data on children's living arrangements and relationship to the head of the household are available, and, in most cases, already collected but not extracted or analyzed systematically, points to a gap that can be relatively easily addressed without major investment of resources or time. What is lacking at this stage is clear guidance for data collection agencies and data users, including national authorities, UNICEF country offices, policy and research bodies as well as donors, about the importance of these data and how they can be systematically extracted and used.

Guidance should include information regarding the impact of omitting these important indicators from the survey during planning and preparation at the country level. Direction to prevent such omissions would ensure that data be systematically collected by all countries undertaking a DHS or MICS survey. When the authors reviewed the latest available DHS and MICS surveys, we found that many countries had never collected the data for parental survival status, including Argentina in its MICS and Angola and Bangladesh in their DHS. Even more concerning, some countries, such as Indonesia, Kenya, Morocco, and the Philippines, had collected parental survival data but subsequently appear to have dropped the question in the household questionnaire of their latest DHS. We must understand why these critical indicators get dropped and work with national statistical authorities and agencies to support their inclusion and publication to ensure that the data can be made available and used easily.

The authors believe that adding an additional table to DHS and MICS country survey reports would enable researchers and policy makers to easily conduct critical analyses of these data to inform policies and programs without having to find additional resources to extract and analyze these datasets. An example of such a table is provided in the Appendix. In addition, data on the child to household head relationship for children who are not living with a biological parent could easily be added to the impressive set of indicators made readily available by the online "STATS Compilers" tools provided online by the DHS Program and the UNICEF MICS team (ICF International 2012; UNICEF 2009). Such inclusion would have limited cost implications for these programs and hugely increase access to these key indicators to researchers across the world, including those working in resource-constrained contexts.

Better mining of the existing datasets under DHS and MICS will be a significant first step to enable more complex analyses of children's living arrangements and to some extent care arrangements too. Yet, looking forward, with relatively small amendments to both questionnaires, the quality of these data could also be enhanced dramatically in the existing surveys. Modifications that enable better understanding of the dynamic communications and relationships of the child, such as contact with nonresident parents, and additional information regarding the child's primary caregiver are two such areas. Currently, the MICS questionnaire for children under 5 is already targeting the "caretaker" of these children living without their biological mother. One modification could simply be extending these specific questions to all children not coresiding with a biological parent to enable analysis beyond children's living arrangements to children's care arrangements. The MICS women's questionnaire is already collecting important information from women about their children living out of the household, including whether these children are alive or dead. This important question could be significantly strengthened by asking the whereabouts of children who are alive but not living with the mother, including whether they are living with relatives or whether they have been placed in residential care. The household questionnaire under MICS also asks questions as part of the list of household members on the whereabouts of the natural mother or father if either of these latter is not a coresident, including whether the parent is "in another household," "abroad," or "in an institution" in the country. To provide critical data on children placed in residential care, this question could be bidirectional, also being asked to women to capture the whereabouts of their children. This option could help minimize the dearth of data on children living outside of households. The MICS 5 questionnaire has already been revised to include a question on biological parents living abroad, enabling important information to be gathered on the growing issue of parental migration. These data will be very important to understanding the growing issue of "children left behind" through 
international migration and enable more comprehensive analysis to be done on the correlation between this and child well-being.

These relatively minor changes would result in far more comprehensive analyses being done on children's living and care arrangements and would substantially contribute to the important analyses of child and family vulnerability to separation and risk factors to placement in alternative care, including residential care in low- and middle-income countries. Enacting these changes would enable these countries to begin building on the types of data collection and analyses available to high-income countries to support informed policies and services for children at risk.

\section{Conclusion}

This article has argued that it is time to move away from a perspective of children's care that sees orphanhood as the only or even primary indicator of vulnerability. While losing a parent is certainly a marker of vulnerability, the evidence from research has shown that a child's living arrangement, whom that child lives with, is even more important than whether or not he or she has a parent (UNICEF 2014). The reality that the vast majority of children who are orphaned are in the care of their extended family is finally being recognized in efforts to strengthen family care and the capacity of both single parent and other members of the child's family to care adequately for them.

DHS and MICS data, if appropriately disaggregated and analyzed, can provide powerful information about trends and patterns in children's living arrangements and care situations, which are essential to understanding the relationship between these specific contexts and a number of important indicators of child well-being contained in those surveys. Together with data on children "outside of households," these data will allow for a more comprehensive picture of child care patterns that exist locally, regionally, and globally. In the absence of other studies, in particular longitudinal ones, the use of existing surveys has the potential to strengthen evidence on the risks and protective factors that may lead to loss of parental care, child and family separation, and the need for alternative care. Such evidence, in turn, is essential to inform and deliver effective family strengthening policies and services. In the era of "data for development" (SDSN 2015) this constitutes a "low hanging fruit" with considerable returns for little investment to measure and improve child well-being globally.

Acknowledgments This research was supported in part by a grant from the Displaced Children and Orphans Fund and the Office of HIV/AIDS of USAID.

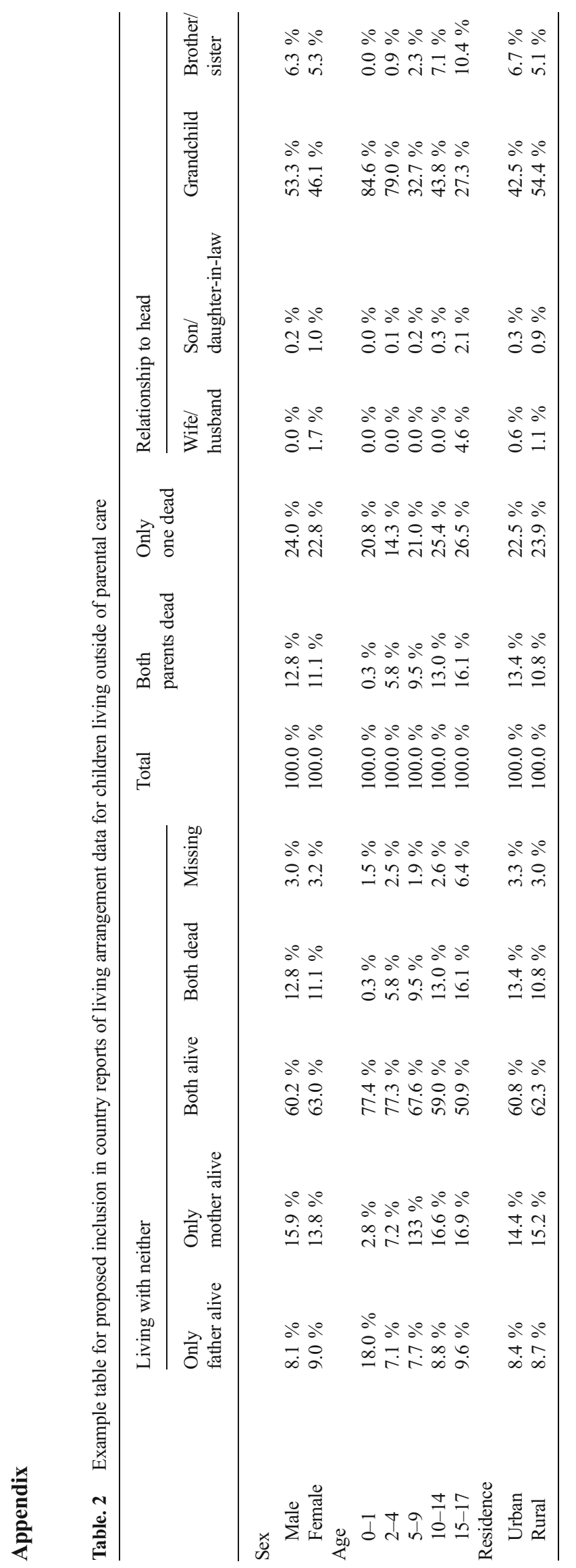




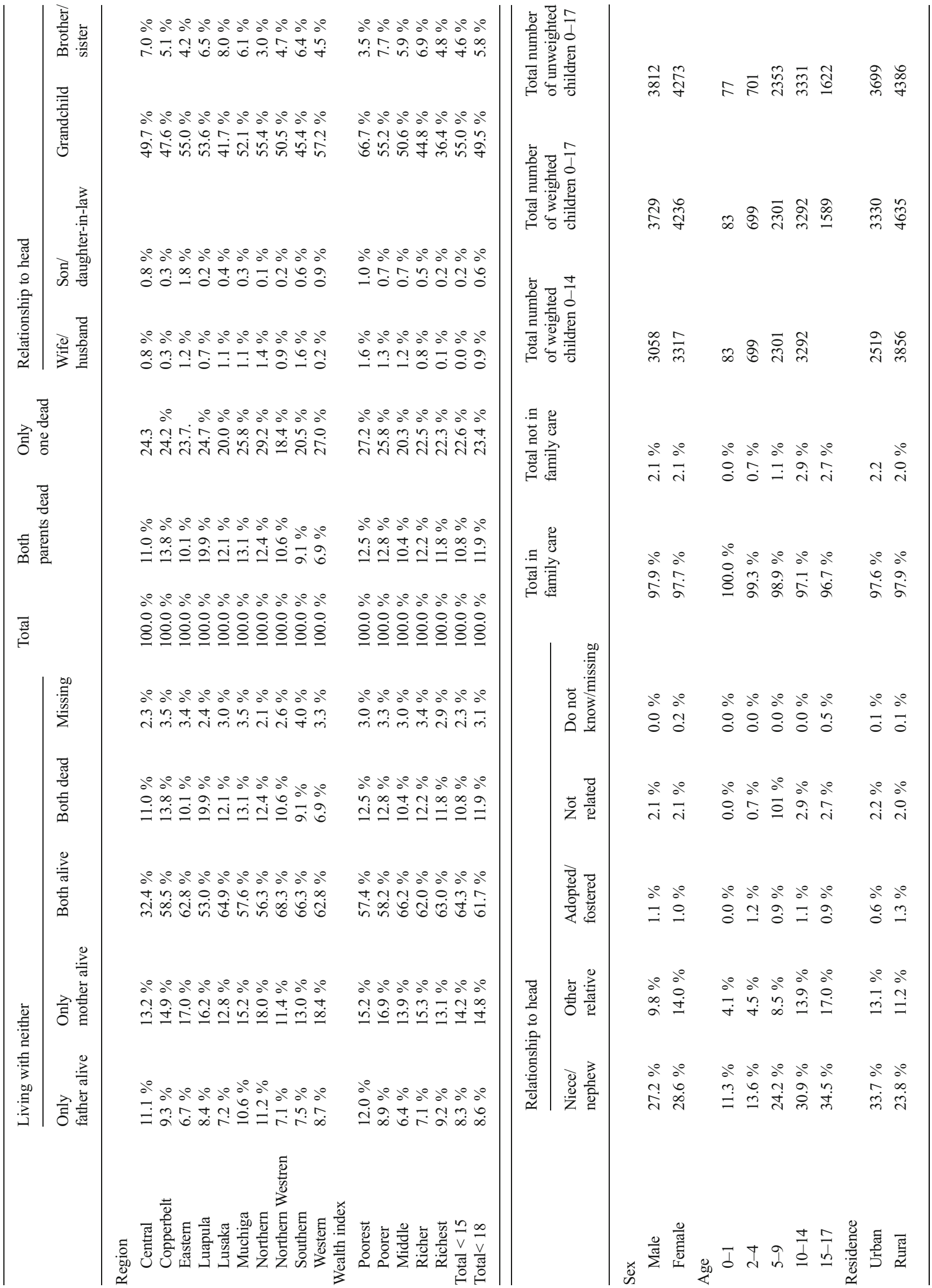




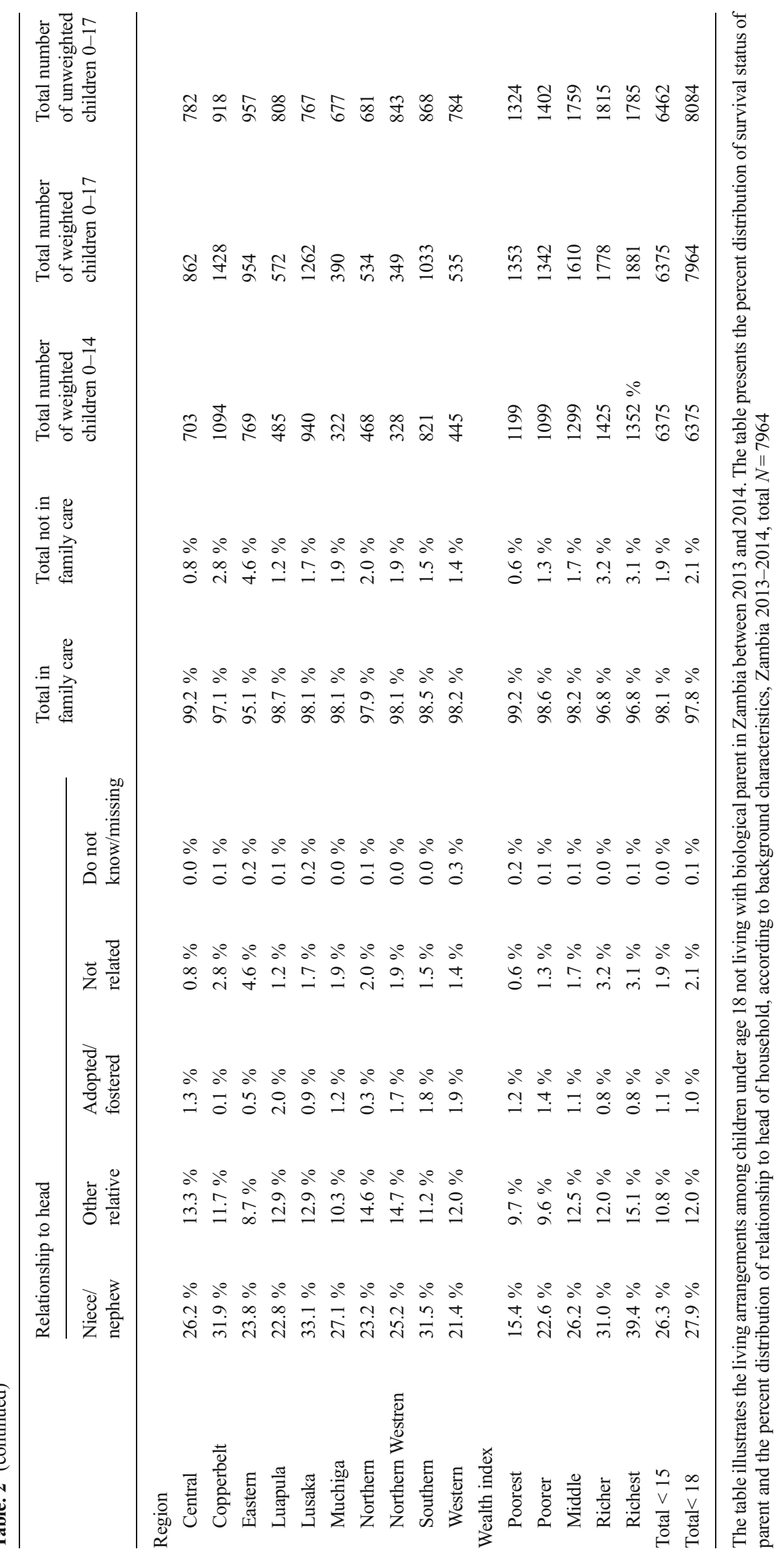


Open Access This article is distributed under the terms of the Creative Commons Attribution 4.0 International License (http:// creativecommons.org/licenses/by/4.0/), which permits unrestricted use, distribution, and reproduction in any medium, provided you give appropriate credit to the original author(s) and the source, provide a link to the Creative Commons license, and indicate if changes were made.

\section{References}

Abebe, T. (2009). Orphanhood, poverty and the care dilemma: review of global policy trends. Social Work and Society, 7(1), 70-85.

Abebe, T., \& Aase, A. (2007). Children, AIDS and the politics of orphan care in Ethiopia: the extended family revisited. Social Science \& Medicine, 64(10), 2058-2069.

Ainsworth, M., \& Filmer, D. (2006). Inequalities in children's schooling: AIDS, orphanhood, poverty, and gender. World Development, 34(6), 1099-1128

Akwara, P. A., Noubary, B., Lim Ah Ken, P., Johnson, K., Yates, R., Winfrey, W., \& Luo, C. (2010). Who is the vulnerable child? Using survey data to identify children at risk in the era of HIV and AIDS. AIDS Care, 22(9), 1066-1085.

Apata, T., Rahji, M., Apata, O., Ogunrewo, J., \& Igbalajobi, O. (2010). Effects of HIV/AIDS epidemic and related sicknesses on family and community structures in Nigeria: evidence of emergence of older care-givers and orphan hoods. Journal of Science and Technology Education Research, 1(4), 73-84.

Bakermans-Kranenburg, M. J., Bos, K., Bunkers, K. M., Dobrova-Krol, N. A., Engle, P. L., Fox, N. A., \& Greenberg, A. (2011). Children without permanent parents: research, practice, and policy. Monographs of the Society for Research in Child Development, 76(4), 1-318.

Beegle, K., Filmer, D., Stokes, A., \& Tiererova, L. (2009). Orphanhood and the living arrangements of children in sub-Saharan Africa. World Bank Policy Research Working Paper Series, Vol.

Belsey, M. A., \& Sherr, L. (2011). The definition of true orphan prevalence: trends, contexts and implications for policies and programmes. Vulnerable Children and Youth Studies, 6(3), 185-200.

Berens, A. E., \& Nelson, C. A. (2015). The science of early adversity: is there a role for large institutions in the care of vulnerable children? The Lancet.

Better Care Network. (2013). Analysis of DHS data (Ghana, Liberia, Rwanda, Jordan, Sierra Leone). Better Care Network. Unpublished.

Better Care Network. (2015a). Zambia DHS 2013-2014: Children's Care and Living Arrangements. Data and Monitoring. Better Care Network. New York, NY. Retrieved 12 September 2015, from http:// bettercarenetwork.org/library/social-welfare-systems/data-andmonitoring-tools/zambia-children $\% \mathrm{E} 2 \% 80 \% 99$ s-care-and-livingarrangements-dhs-2013-14.

Better Care Network. (2015b). Ethiopia DHS 2011: Children's Care and Living Arrangements. Better Care Network. New York, NY. Retrieved 12 September 2015, from http://bettercarenetwork.org/ library/social-welfare-systems/data-and-monitoring-tools/ethiopiachildren $\% \mathrm{E} 2 \% 80 \% 99$ s-care-and-living-arrangements-dhs- 2011 .

Better Care Network. (2015c). Uganda DHS 2011: Children's Care and Living Arrangements. Data and Monitoring. Better Care Network. New York, NY. Retrieved 12 September 2015, from http:// bettercarenetwork.org/library/social-welfare-systems/data-andmonitoring-tools/uganda-children $\% \mathrm{E} 2 \% 80 \% 99$ s-care-and-livingarrangements-dhs-2011.

Better Care Network. (2015d). Nigeria DHS 2013: Children's Care and Living Arrangements. . Better Care Network. New York, NY.
Retrieved 25 September 2015, from http://bettercarenetwork.org/ library/social-welfare-systems/data-and-monitoring-tools/nigeriachildren $\% \mathrm{E} 2 \% 80 \% 99$ s-care-and-living-arrangements-dhs-2013.

Better Care Network \& UNICEF (2015a). An Analysis of Child-Care Reform in Three African Countries: Summary of Key Findings. New York, USA. Retrieved 25 September 2015, from http://www. bettercarenetwork.org/bcn-in-action/technical-guidance/countrycare-profiles/an-analysis-of-child-care-reform-in-three-africancountries-summary-of-key-findings.

Better Care Network \& UNICEF (2015b). Country Care Profile: Liberia. New York, USA. Retrieved 25 September 2015, from http://www. bettercarenetwork.org/ben-in-action/technical-guidance/countrycare-profiles/country-care-profile-liberia.

Bicego, G., Rutstein, S., \& Johnson, K. (2003). Dimensions of the emerging orphan crisis in sub-Saharan Africa. Social Science \& Medicine, 56(6), 1235-1247.

Bowlby, J. (1982). Attachment and loss: retrospect and prospect. American Journal of Orthopsychiatry, 52(4), 664.

Bowlby, J., Fry, M., \& Ainsworth, M. D. S. (1965). Child care and the growth of love. London: Penguin Books.

Browne, K. (2005). A European Survey of the Number and Characteristics of Children Less than Three Years Old in Residential Care at Risk of Harm. Adoption and Fostering, 29(4), 23-33. doi:10.1177/030857590502900405.

Browne, K. (2009). The risk of harm to young children in institutional care: Better Care Network and Save the Children. Retrieved 14 April 2015, from http://bettercarenetwork.org/sites/default/files/ The $\% 20$ Risk $\% 20$ of $\% 20$ Harm $\% 20$ to $\% 20$ Young $\% 20$ Children $\%$ 20 in\%20Institutional\%20Care.pdf.

Browne, K., Hamilton-Giachritsis, C., Johnson, R., \& Ostergren, M. (2006). Child health: overuse of institutional care for children in Europe. BMJ [British Medical Journal], 332(7539), 485.

Campbell, P., Handa, S., Moroni, M., Odongo, S., \& Palermo, T. (2010). Assessing the "orphan effect" in determining development outcomes for children in 11 eastern and southern African countries. Vulnerable Children and Youth Studies, 5(1), 12-32.

Carter, R. (2005). Family matters: a study of institutional childcare in Central and Eastern Europe and the Former Soviet Union. London: Everychild.

Case, A., Paxson, C., \& Ableidinger, J. (2004). Orphans in Africa: parental death, poverty, and school enrollment. Demography, 41(3), 483-508.

Child Frontiers. (2012). Family support services and alternative care in Sub-Saharan Africa: background paper. Hong Kong: Child Frontiers.

Child Trends. (2013). World Family Map: Mapping Family Change and Child Well-Being Outcomes: Child Trends

Child Trends. (2014). World Family Map: Mapping Family Change and Child Well-Being Outcomes- Family instability and early childhood health in the developing world. : Child Trends.

Child Protection Monitoring and Evaluation Reference Group (CP MERG) (2014). Terms of Reference. New York: Better Care Network. Retrieved 12 September 2015, from http://www.cpmerg. org/technical-working-groups/.

Csaky, C. (2009). Keeping children out of harmful institutions: why we should be investing in family based care. London: Save the Children. Retrieved 8 April 2016, from http://www. savethechildren.org.uk/resources/online-library/keepingchildrenout-of-harmful-institutions-why-we-should-be-investing-infamilybased-care.

DESA/UNSD. (2005). ST/ESA/STAT/SER.F/96 Department of Economic and Social Affairs Statistics Division Studies in Methods Series F No. 96 Household Sample Surveys in Developing and Transition Countries. New York: United Nations.

DHS Program Overview. (2015). Retrieved 25 June 2015, http:// dhsprogram.com/What-We-Do/Survey-Types/DHS.cfm.

DHS. (2015). Establishment of a Collaborative Group among the DHS, MICS and LSMS Press Release. Retrieved 25 June 2015 from 
http://dhsprogram.com/Who-We-Are/News-Room/Establishmentof-a-Collaborative-Group-among-the-DHS-MICS-and-LSMS.cfm

DHS implementing partners and ICF International. (2000-2015). Demographic and Health Surveys Standard Demographic and Health Series (SDHS), (Vol. version 2.0).

Drah, B. (2012). Orphans in Sub-Saharan Africa: The Crisis, the Interventions, and the Anthropologist. Africa Today, 59(2), 3-21. http://doi.org/10.2979/africatoday.59.2.3

EveryChild, \& HelpAge International. (2012). Family first: Prioritising support to kinship carers, especially older carers. London: EveryChild and HelpAge International.

Fox, N. A., Almas, A. N., Degnan, K. A., Nelson, C. A., \& Zeanah, C. H. (2011). The effects of severe psychosocial deprivation and foster care intervention on cognitive development at 8 years of age: findings from the Bucharest Early Intervention Project. Journal of Child Psychology and Psychiatry, 52(9), 919-928.

Hosegood, V. (2008). Demographic evidence of family and household changes in response to the effects of HIV/AIDS in southern Africa: Implications for efforts to strengthen families. Retrieved 14 April 2015, from http://www.hsrc.ac.za/uploads/pageContent/1265/2008 HosegoodDemographicevidenceoffamilyandhouseholdchanges inresponsetotheeffectsofHIVandAIDSLG1StrengtheningF.pdf.

Hunter, S., \& Williamson, J. (1997). Children on the brink: Strategies to support children isolated by HIV/AIDS. Arlington: USAID.

ICF International. (2012). The DHS Program STATcompiler. Retrieved 25 June 2015, http://www.statcompiler.com.

Family For Every Child \& INTRAC. (2012). Context for Children and Policy situation paper, Family for Every Child. London: Family For Every Child and INTRAC.

JLICA. (2009). Home Truths: Facing the Facts on Children, AIDS and Poverty. London: Final report of the Joint Learning Initiative on Children and AIDS.

Johnson, D. E., \& Gunnar, M. R. (2011). IV. Growth failure in institutionalized children. Monographs of the Society for Research in Child Development, 76(4), 92-126.

Leder, S., Grinstead, L. N., \& Torres, E. (2007). Grandparents raising grandchildren stressors, social support, and health outcomes. Journal of Family Nursing, 13(3), 333-352.

Magadi, M. A. (2011). Household and community HIV/AIDS status and child malnutrition in sub-Saharan Africa: evidence from the demographic and health surveys. Social Science \& Medicine, 73(3), 436-446.

Martin, F., \& Sudrajat, T. (2007). Someone that matters: The quality of care in childcare institutions in indonesia. Jakarta: Save the Children UK/The Ministry of Social Affairs (DEPSOS)/UNICEF. Retrieved 12 September 2015, from http://bettercarenetwork.org/ library/social-welfare-systems/child-care-andprotection-systemreforms/indonesia-changing-the-paradigm-save-thechildren $\% \mathrm{C} 2 \%$ $80 \% \mathrm{C} 2 \% 99$ s-work-to-strengthen-the-child-protection-system.

McCall, R. B., Groark, C. J., \& Rygaard, N. P. (2014). Global research, practice, and policy issues on the care of infants and young children at risk: the articles in context. Infant Mental Health Journal, 35(2), 87-93.

Meintjes, H., \& Giese, S. (2006). Spinning the Epidemic The making of mythologies of orphanhood in the context of AIDS. Childhood, 13(3), 407-430.

Meintjes, H., Hall, K., Marera, D., \& Boulle, A. (2009). Child-headed households in South Africa: a statistical brief. Cape Town: Children's Institute, University of Cape Town.

Meintjes, H., Moses, S., Berry, L., \& Mampane, R. (2007). Home truths: the phenomenon of residential care for children in a time of AIDS. Children's Institute

MICS implementing partners, \&UNICEF. (2000-2014). Multiple Indicator Cluster Surveys (selected countries) Final Report. Statistics and Monitoring Section, Division of Policy and Strategy,
United Nations Children's Fund. New York. Retrieved 25 September 2015 from http://mics.unicef.org/surveys.

Mishra, V., \& Bignami-Van Assche, S. (2008). Orphans and vulnerable children in high HIV-prevalence countries in Sub-Saharan Africa

Monasch, R., \& Boerma, J. T. (2004). Orphanhood and childcare patterns in sub-Saharan Africa: an analysis of national surveys from 40 countries. AIDS, 18, S55-S65.

Shailen Nandy, S., \& Selwyn, J. (2013). Kinship care and poverty: using census data to examine the extent and nature of kinship care in the UK. British Journal of Social Work, 43(8), 1649-1666.

National Scientific Council on the Developing Child. (2012). The science of neglect: the persistent absence of responsive care disrupts the developing brain: Working Paper 12. Retrieved 12 September 2015 from http://www.developingchild.harvard.edu.

Nelson, C. A., Bos, K., Gunnar, M. R., \& Sonuga-Barke, E. J. (2011). V. The neurobiological toll of early human deprivation. Monographs of the Society for Research in Child Development, 76(4), 127-146.

Nyamukapa, C., \& Gregson, S. (2005). Extended family's and women's roles in safeguarding orphans' education in AIDS-afflicted rural Zimbabwe. Social Science \& Medicine, 60(10), 2155-2167.

OECD. (2010). SF1.3: Living arrangements of children OECD. Retrieved 11 September 2015, from http://www.oecd.org/els/ social/family/database.

OECD. (2011). Doing Better for Families. Paris: OECD. Retrieved 11 September 2015, from http://www.oecd.org/els/soc/ doingbetterforfamilies.htm.

OECD. (2015). OECD Family Database. Paris: OECD. Retrieved 11 September 2015, from http://www.oecd.org/els/social/family/ database.

Pullum, T., Cappa, C., Orlando, J., Dank, M., Gunn, S., Mendenhall, M., \& Riordan, K. (2012). Systems and strategies for identifying and enumerating children outside of family care. Child Abuse \& Neglect, 36(10), 701-710.

Richter, L. M., Manegold, J., \& Pather, R. (2004). Family and community interventions for children affected by AIDS: HSRC Press

Richter, L. M., Sherr, L., Adato, M., Belsey, M., Chandan, U., Desmond, C., \& Kimou, J. (2009). Strengthening families to support children affected by HIV and AIDS. AIDS Care, 21(S1), 3-12.

Roby, J. (2011). Children in informal alternative care. New York: UNICEF, Child Protection Section.

Roy, P., Rutter, M., \& Pickles, A. (2004). Institutional care: associations between overactivity and lack of selectivity in social relationships. Journal of Child Psychology and Psychiatry, 45(4), 866-873.

Save the Children. (2013). "Yaro Na Kowa Ne" Children belong to everyone. Save the Children Research Initiative: Understanding and Improving Informal Alternative Care Mechanisms to increase the care and protection of children, with a focus on Kinship care in West Central Africa. Retrieved 8 April 2016 from http:// resourcecentre.savethechildren.se/sites/default/files/documents/ kinship_care_report_final.pdf.

Schoenmaker, C., Juffer, F., van IJzendoorn, M. H., \& BakermansKranenburg, M. J. (2014). Does family matter? The well-being of children growing up in institutions, foster care and adoption Handbook of child well-being (pp. 2197-2228): Springer.

SDSN. (2015). Data for Development: A Needs Assessment for SDG Monitoring and Statistical Capacity Development. April 17, 2015. The Sustainable Development Solutions Network. Retrieved 12 September 2015, from: http://unsdsn.org/wp-content/uploads/2015/ 04/Data-for-Development-Full-Report.pdf.

Sherr, L., Varrall, R., Mueller, J., Richter, L., Wakhweya, A., Adato, M., \& Haour-Knipe Victoria Hosegood, M. (2008). A systematic review on the meaning of the concept 'AIDS Orphan': confusion over definitions and implications for care. AIDS Care, 20(5), 527-536.

Shonkoff, J. P., \& Phillips, D. A. (2000). Committee on Integrating the Science of Early Childhood Development, Board on Children, 
Youth, and Families. From Neurons to Neighborhoods: The Science of Early Childhood Programs.

Sonuga-Barke, E. J., \& Kreppner, J. (2012). The development and care of institutionally reared children. Child Development Perspectives, $6(2), 174-180$.

Sroufe, L. A. (2005). Attachment and development: a prospective, longitudinal study from birth to adulthood. Attachment \& Human Development, 7(4), 349-367.

The Annie E. Casey Foundation. (2015). Children living with neither parent. In K. C. D. Center (Ed.), National KIDS COUNT. The Annie E. Casey Foundation.

UN General Assembly. (1989). Convention on the Rights of the Child. United Nations, Treaty Series, 1577(3).

UN General Assembly. (2009). Guidelines for the alternative care of children. New York: UN. Retrieved November 13 2015, from http://bettercarenetwork.org/library/social-welfare-systems/ standards-ofcare/guidelines-for-the-alternative-care-of-childrenenglish.

UNAIDS, UNICEF \& USAID. (2004). Children on the Brink 2004: A joint report of new orphan estimates and a framework for action. Population, Health and Nutrition Project for USAID, Washington, DC, 2

UNAIDS. (2015). AIDSinfo. Retrieved 13 September 2015 from http:// aidsinfo.unaids.org/.

UNICEF. (2004). The framework for the protection, care and support of orphans and vulnerable children living in a world with HIV and AIDS. Technical and policy documents, UNICEF

UNICEF. (2006). Africa's Orphaned and Vulnerable Generations: Children Affected by AIDS: Unicef.

UNICEF. (2009). Multiple Indicator Cluster Survey - MICS Compiler. UNICEF, DevInfo. Retrieved 11 September 2011, from http://www.childinfo.org/mics.html.

UNICEF. (2011). Taking evidence to impact: Making a difference for vulnerable children living in a world with HIV and AIDS. New York: UNICEF. Retrieved 12 September 2015, from http://www.
unicef.org/aids/files/Taking_Evidence_to_Impact_w_Logos FINAL.pdf.

UNICEF. (2014). Measuring the determinants of childhood vulnerability, New York: UNICEF. Retrieved 31 August 2015, from http://data. unicef.org/corecode/uploads/document6/uploaded pdfs/corecode/ Measuring-the-Determinants-of-Childhood-Vulnerability_FinalReport-5 8-LR-172.pdf.

US Census Bureau. (2012) Families and Living Arrangements. US Census Bureau. Retrieved 15 September 2015, from http:// www.census.gov/hhes/families/.

USAID. (2014). Center of Excellence on Children in Adversity: About. USAID. Retrieved 12 September 2015, from: http://www. childreninadversity.gov/about.

US Government. (APCA). (2012). United States Government Action Plan on Children in Adversity. A Framework for International Assistance: 2012-2017. U.S. Department of State, U.S. Department of Labor, U.S. Department of Agriculture, U.S. Department of Defense, U.S. Department of Health and Human Services, U.S. Agency for International Development and Peace Corps.

van IJzendoorn, M. H., Palacios, J., Sonuga-Barke, E. J., Gunnar, M. R., Vorria, P., McCall, R. B., \& Juffer, F. (2011). I. Children in institutional care: delayed development and resilience. Monographs of the Society for Research in Child Development, 76(4), 8-30.

Waldfogel, J., Craigie, T.-A., \& Brooks-Gunn, J. (2010). Fragile families and child wellbeing. The Future of children/Center for the Future of Children, The David and Lucile Packard Foundation, 20(2), 87.

Williamson, J., \& Greenberg, A. (2010). Families, not orphanages. New York: Better Care Network. Retrieved 8 April 2016, from http:// www.bettercarenetwork.org/library/the-continuum-of-care/ fostercare/families-not-orphanages.

The World Bank. (2015). Country and Lending Groups. Data. 2015, retrieved 12 September 2015, from http://data.worldbank.org/ about/country-and-lending-groups. 